UC.23

Reporting Date: June 1976

Issued: July 1976

\title{
A Bayesian Zero-Failure (BAZE) Reliability Demonstration Testing Procedure and Its \\ Application to a Rankine Dynamic Radioisotope Power Conversion System
}

\author{
by
}

H. F. Martz, Ir.

R. A. Waller

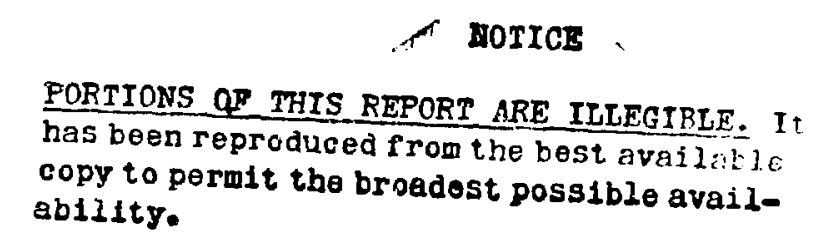

alamos

selentitio laboratory

of the University of California

los alamos, NeW MEXICO 87545

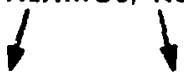

An Affirmalive Action / Equal Opporfunity Employer 
Work supported by the US Energy Research and Development Administration, Division of Nuclear Research and Applications.

Printed in the United States of America. Available from National Technical Information Service

U.S. Department of Commerce 5285 Port Royal Road Springfield, VA 2216i

Price: Printed Copy $\$ 4.50$ Microfiche $\$ 2.25$

This repert was preared an an sawnet of work nopnoored ov the United Statex Governmeat. Neilluer the United Shates

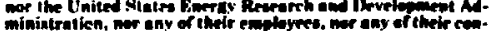

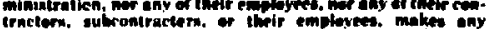

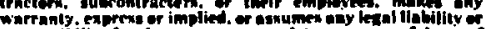

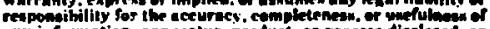

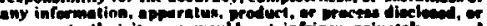

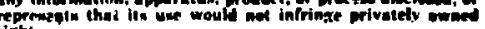




\section{CONTI:STS}

Notation................. . . . . . . .

I. Introduction and purpose. . . . . . . . . . . . I

11. Roliability Demonstration Tresting . . . . . . . . . . 3

III. Bayesian Zero-lialure(BAZE) Reliabjlity

Demonstration Test Plans for Time-Dependent

Chance Failure Mechanisms . . . . . . . . . . . 6

IV. Prior Distributions litted to Components

of a Proposed Rankine Power

Conversion System . . . . . . . . . . . . I7

. BAzl: Test Plans for Components of a Proposel

Rankine lower Conversion System . . . . . . . . 22

11. Mdditional Considerations and Conclusions . . . . . 23

lppendix... . . . . . . . . . . . . . . . . 45

Table Al. Values of $\theta_{y}$ for Selected Valles

of Prior Shape Parameter (a) and posterior

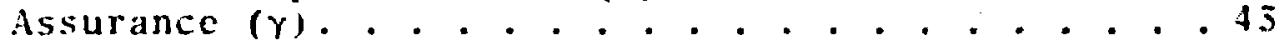

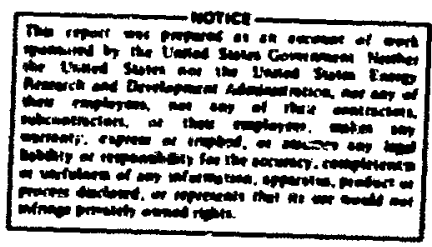




\section{$\operatorname{sot} 110 x$}

a

b

$B A=1$ :

BIDS

$\delta_{0}$

[:RI).

r(i)

$f(\lambda \mid 0$ failures $)$

HWII:A

$\gamma$

$(1-Y)$

$I(a, x)$

$k$

KIPS

$\lambda$

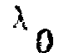

$x *$

m

$M F R$

MMI)

ก

$n_{0}$

iv

$(n N)_{0}$

$n t$
- prior shape parameter

- prior scalo parameter

- Bayesian Eero lailure

- Bration liotope Power System

- specified cycle fajlure-rate failuresl cyelel

- lineryy Researeh and nevelopment Adninistration

- prior probahility densitv function of the failitre-rate $\lambda$

- postcrior probability density function of the fajlure-rate h conditional on observed fillures in a test of nt unit-hours

- Vililure lode and lifrects Analysis

- posterior assurance

- postcrior risk

- incomplete gamma function

$-\int_{0}^{x} y^{a-1} c^{-y} d y$

- discrinination ratio (A/ $\left./{ }_{0}\right)$

- Kilowat lsutope bover system

- fatilure-rate

- specified faliure-rate

- critcrion failure-rate $\left.(k)_{0}\right)$

- generic fablure-rate

- required component duty cycle

- Median fililure Rate

- Mean Mission Duration

- number of test units

- required number of test units

- number of test cyeles

- required unit -cycles of testing

- unit-hours of testing 


\begin{tabular}{|c|c|}
\hline $\begin{array}{l}\left.(n+)_{0}\right) \\
p(\cdot)\end{array}$ & $\begin{array}{l}\text { - required unit-hours of testing } \\
\text { - Probability }\end{array}$ \\
\hline$P(x$ railures $\mid a)$ & $\begin{array}{l}\text { - conditional probability of } x \text { failures in } \\
\text { a test of nt unit-hours with an under- } \\
\text { lying failurc-ratc of } \lambda \text { for each item } \\
\text { - unconditional probability of passing the } \\
\text { BAzl: test }\end{array}$ \\
\hline io failures $\mid \lambda_{*} \leq \lambda \leq \lambda^{*}$ ) & $\begin{array}{l}\text { conditional probability of passing the } \\
\text { RAzl: test }\end{array}$ \\
\hline$P(x$ failures $)$ & $\begin{array}{l}\text { - unconditional probability of } x \text { failures } \\
\text { in a test of nt unit-hours }\end{array}$ \\
\hline * $(x$ failures $)$ & $\begin{array}{l}\text { conditional probability that the fail- } \\
\text { wr-rate is contalned in the interval } \\
{\left[{ }_{*}, *\right] \text { given } x \text { failures in a test of nt }} \\
\text { unit-hours }\end{array}$ \\
\hline PCs & Pover Conversion systcm \\
\hline por: & - Postcrior Operat ing Characteristic \\
\hline RTr; & - Radioisotope Thermoclectric cienerator \\
\hline 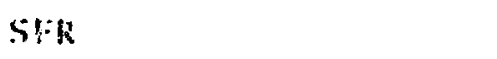 & - Specified lailure Rate \\
\hline ixs & - Space Nuclear Systems \\
\hline$y$ & $\begin{array}{l}\text { lon(y)th percentile of the standard gamma } \\
\text { distribution }\end{array}$ \\
\hline 0 & $\begin{array}{l}\text { - required test duration } \\
\text { - rest duration }\end{array}$ \\
\hline & - failure-tine random variable \\
\hline
\end{tabular}


A BAYESIAN ZERO-FAILURE (BAZE) RELIABILITY

DEMONSTRATION TESTING PROCEIDURE AND ITS APPLICATION

TO A RANKINE DYNAMIC RADIOISOTOPE POWER CONVERSION SYSTEM

by

II. F. Martz, Jr, and R. $\Lambda$, Waller

ABSTRACT

A Bayesian Zero-Failure (BAZE) reliability demonstration testing procedure is developed. The procedure may be used to verify component failure rates associated with both real-time dependent and cycle-dependent chance failure mechanisms. A constant failure-rate model with a gamma prior distribution is assumed. The proiedure is used to obtain sample test plans for components of a proposed Rankire power conversion system.

I. INTRODUCTION AND PURPOSE

Most government and military contracts for hardware development include a numerical reiiability requirement in the specifications. For example, consider the Space Nuclear division, LRDA, proposal solicitation No. SNS-RFP-75-2-CAO, November 4, 1974, regarding the Kilowatt Isotope Power System (KIPS) Ground Demonstration Unit. This is a Phase I project within the overall yroposed KIPS program. The system is to meet a 1 ifetime requirement of 7 years and a mean mission duration (IMD) of 5 years. To satisfy that specification, the system must have a failure-rate $\lambda$ of no more than $11.64 \times 10^{-6}$ failures/hr. In addition, most contracts require quantitative assurance that the minimum acceptable reliabiiity requirement, e.g., the system failure-rate above, has been 
achieved. For example, the document SNS-2 entitled "Reliability lengineering program Requirements Publication," Space Nuclear Systems, ERDA, states in Section 5.2 that "the contractor shall pro$v$ ide the test requirements needed to roasonably assure Sis of demonstration of the minimum acceptable reliability." A typical reliability demonstration statement is that a system failure-rate requirement of $X$ failures/hr. be demunstrated with $Y_{0}^{\circ}$ confidence.

Future dynamic radioisctope power conversion systems will likely require stringent reliability specifications becaus the missions are of lengthy duration. In addition, such systems are necessarily more complex than present static radioisotope thermoelectric generator (RTC) systems because of higher power output requirements. In order to quantitatively demonstrate system conformance to such high reliability requirements, pertinent resourceeffective and statistically sound test plans must be developed. In early consideration of such plans has numerous benefits. lirst, the early availability of these plans will permit adequate planning of scarce resources such as test facilities, test budget, personnel, etc. Second, the carly availability of such plans will assist in determining the number of components to be produced for testing purposes. Third, and perhaps the most important bencfit of carly demonstration test planning is that the required test duration is determined early in the program. This is a valuable aid in developing an efficient program plan which best utilizes available resources. Another relevant consideration when testing high-reliability systems, such as the KIPS and Bratton Isotope Power System (BIPS), is as follows: For high-reliability hardware, traditional (classical) test plans usually are not as resource-eftective as Bayesian test plans. For illustration, suppose specifications require verification that a component has a failure-rate no greater than $3.5 \times 10^{-6}$ failures/hr. With at least $50 \%$ confidence. Assuming a constant failure-rate model and classical test plans, 198,029 unit-hours of testing with no failures is required. On the other hand, a corresponding Bayesian test plan requires only 117,829 unit-hours of testing with no failures. However, it is remarked 
that the Bayesian plan requires the use of so-called "prior information" (sec section [I). Thus, in this example, the use of Bayesian plans yiclds a 68 o test resource improvement over the classical plans. This illustrates one attractive and practical aspect of Bayesian test plans, particularly to the contractor.

The purpose of this report is to develop a general Bayesian Eero-lailure (BAZl) reliability demonstration testing procedure which can be used to demonstrate component/subsystem/system reliability conformance to stated requirements. The procedure presented is a general one and its usc is not restricted to power conversion systems. However, it is used here to develop test plans for verifying ti.e rellability of components of a proposed Rankine ground demonstration power conversion system (PCS). This system is being developed by Sundstrand linergy systems, the prime contractor for tl:e kips program.

$\therefore$ general discussion and introduction to both classical and Bayesian methods is presented in Section II. The BAzE procedure is developed in Section III. Section IV describes the procedure used to fit prior distributions to components of a proposed Rankine PCS. Section $l$ presents a selection of sample reliability demonstration test plans for component verification of the Rankine PCS. Finally, some additional comments regarding cycle-dependent chance failure mechanisms and component level testing with a system's requirement are presented in Section VI. A summary and some conclusions are also siven in Section VI.

\section{RELIABILITY DENONSTRATION TESTING}

Over the past two decades numerous classical reliability demonstration testing methods have been devisec for various failuretime distributions. Classical demonstration test plans for components having an exponential failure-time distribution (constant failure-rate) may be fixed time (Type I Censoring), fixed number of failures (Type II Censoring), or sequential tests. In addition, such tests may be conducted either with or without the replacement of failed items when failures occur during the test. One example 
of a classical procedure is MIL-STD- $781 \mathrm{C}$ wich gives virious test procedures derived under the assumption of a constant failure-rate. These tests are based on various levels of producer's and consumer's risk, discrimination ratios, and the confidence level of the test. In these tests, a simple statistical hypothesis of the form

$$
\begin{aligned}
& \text { H: } \lambda=\lambda_{0} \text { (specified fajlure-rate) } \\
& \lambda: \lambda=\lambda_{1} \text { (maximum acceptahle failure-rate) }
\end{aligned}
$$

is tested, where $\lambda$ is the (unknown) failure-rate of the device and $\lambda_{1}>\lambda_{0}$. The producer's risk is the probability that, if 11 is true, A will be acceptad, while the consumer's risk is the probability that, if $A$ is true, Hill be accepted. The discrimination ratio is defined as the ratio of $\lambda_{1}$ to $\lambda_{0}$. The text by laim, Schafer, and Singpurwalla (1974) gives an excellent discussion of the basis upon which these and other classical test plans have been developed.

The reliability demonstration testing environment in industry is generally hindered by several inajor constraints. Among the most serious are those due to limited test budget and 1 imited time for conducting the demonstration test. The use of Bayesian methods has recently received a great deal of attention as a means of adhering to such constraints. Basically, the Bayesian idea is to combine two sources of information by use of the well-known Bayes Theorem [see Waller and Martz (1975)]. The resultant test plans are resource-effective, without sacrificing quality protection. Frequently, during the course of a contract, information regarding component performance is acquired by such means as reliability predictions, design, development, and production tests, and the observation of similar products in field use. Such information is referred to as "prior information," since it represents the sum total of engineering judgement and belief concerning componeat performance prior to conducting the demonstration test and observing the test results. The second source of information is the quantitative test results themselves. Both sources of information are combined via Bayes Theorem to produce a statement such as the 
probability that the failure-rate loes not exced the required value is $x_{0}^{\circ}$. baycsian demonstration test plans frequently permit reaching a decision regarding component reliability with fewer test resources than required by classical test plans, as illustrated in Section I. If the prior information supports an adequately reliable component, then less testing will usually be required compared to the classical casc. If the opposite is the case, then more testing may be required. An introduction to the use of Bayesian methods in reliability is given by lialler and Martz (1975), (1976).

One of the carliest references tc Bayesian reliability demonstration plans is that of Bonis (1966). Since that time numerous Baycsian schencs have been developed. Sasterling (1970) presented a somewhat modizicd Baycsian demonstration procedure. Schafer and Singpurwalla (1970)developed a sequential Bayes procedure for obtaining required test plans. Recently, Schafer (1969), (1971), and (1975) has considered three types of Bayesian plans: (1) Baycsian fixed time tests, (2) mixed Bayesian/classical, and (3) Baycsian sequential tests. Following along these same lines, Goel et al rates unknown) developed Bayesian plans for slightly different criteria. Blumenthal (1975) has also developed Bayesian test plan procedures. Guild (1968), (1975) has developed what he refers to as "median failure rate" (NIIR) reliability demonstration plans. Other Bayesian plans have also been considered by Balaban (1969), (1975) and Ramos (1970). Joglekar (1975) discusses several of these Bayesian testing schemes. Recently, Goel and Joglekar [1976 (a) $-1970(c)$ ] have prepared a comprehensive account of the state of the art of Bayesian reliability acceptance sampling. This fivepart series provides an excellent introduction to the subject. One of the najor probiems with most Bayesian test plans is the relative difficulty in obtaining a desired plan in practice. This is due to the presence of additional prior parameters. For example, most of the above Bayesian plans are derived for a constant failure-rate model and a gamma prior distribution on the failurerate [see Waller and Martz (1975)]. 
The gamma prior distribution is the natural conjugate prior distribution for the constant failure-rate model. Schafer (1969) investigated data from 32 different equipments and found that in 29 cases a gamma prior distribution adequately fit the data. Others have likewise observed the suitability and versatility of the gamma prior distribution. For these reasons it is also considered here. However, it is frequently not an easy task to identify an appropriate gamma prior distribution and, once this has been done, to obtain the required test plan. The choice of test plan criteria, e.g., the consumer and producer risks that are to be controlled, can also complicate the determination of the required plan. Certain criteria yield plans that are simple to determine. One of the easiest of the above Bayesian procedures to use in practice is that given by Guild (1973). A more general version of this procedure is developed in the next section for use here. Two somewhat distinctive aspects of the procedure should be mentioned before we begin the development. First, the criterion upon which the procedure is based is simple, pertinent, and easy to grasp. Second, the procedure is straightforward and easy to apply in practice, with only a pocket calculator required for a few simple calculations. Together these provide a useful Bayesian procedure for a large variety of applications. Let us now consider the details of this procedure.

III. BAYESIAN ZERO-FAILURE (BAZE) RELIABILITY DEMONSTRATION TEST PLANS FOR TIME-DEPENDENT CHANCE FAILURE MECHANISMS

This section describes how to construct and apply Bayesian fixed time demonstration test plans of the replacement type, called BAZE plans, for systems/subsystems/components having a constant failure-rate. The BAZE procedure is developed for testing timedependent chance failure mechanisms in this section. Section VI discusses how the procedure may also be used for testing cycledependent chance failure mechanisms. 
To begin, consider a device, henceforth referred to as a "component." having an exponential failure time distribution with failure-rate $\lambda$. (At present we consider a test plan for one such component, while corresponding test plans for series systems of such components is considered in Section VI.) Thus, the failure-time random variable $X$ of this component is assumed to follow the we11known exponential probability density function given by

$$
f(x \mid \lambda)=\lambda e^{-\lambda x}, x \geq 0, \lambda>0 .
$$

It is further assumed here that the prior distribution of $\lambda$ is the natural conjugate gamma distribution with probability density function given by

$$
f(\lambda)=\frac{b^{a}}{\Phi(a)} \lambda^{a-1} e^{-b \lambda}, \lambda, a, b>0,
$$

where $a$ is the prior shape parameter and $b$ is the prior scale parameter. The parameter a can be interpreted as the number of pseudo failures in a prior life test of duration b pseudo hours. The mean and variance of $(2)$ are given by $(a / b)$ and $\left(a / b^{2}\right)$, respectively. Thus, the initial prior estimate of the failure-rate $\lambda$ is $(a / b)$.

The test plans considered here assume that in identical components are tested each for a prespecified length of time $t$, the test duration. The quantities $n$ and $t$ are to be determined consistent with the following statistical test criterion. The test criterion is as follows: if no failures occur, the test is passed, while if one or more failures occur, the test is failed. Thus the test is terminated either at the prespecified test time $t$ or at the time of the first component failure, whichever occurs first. Such "zero-failure" test plans usually require the smallest unit-hour test combination $n t$ for a stated confidence, and are thus test resource-effective. In addition, by restricting consideration to zero-failures, such test plans are easy to obtain. Now the probability of obtaining exactly zero failures during the test is given by

$$
P(0 \text { failures } \mid \lambda)=e^{-n t \lambda} .
$$


The posterior distribution of $\lambda$ is also a gamma distribution with scale parameter $(b+n t)$ and shape parameter a. Thus, conditional on zero failures in nt unit-hours of testing, the posterior probability density function of $\lambda$ becomes

$$
F(\lambda \mid 0 \text { failures })=\frac{(b+n t)^{a}}{\Gamma(a)} \lambda^{a-1} e^{-(b+n t) \lambda} \text {. }
$$

In order to find the required unit-hour test combination nt, some criterion regarding the desired confidence level of the demonstration test must be given. The plans presented here satisfy the posterior risk criterion given by

$$
P\left(\lambda \leq k \lambda_{0} \mid 0 \text { failures }\right)=\gamma \text {, }
$$

where $P(\cdot)$ is a probability function. Here $\lambda_{0}$ is the specified failure-rate. If we define $\lambda_{1} \equiv k \lambda_{0}$, then $\lambda_{1}$ is referred to as the test criterion failure-rate and $k$ is known as the discrimination ratio. The test criterion in (5) is interpreted as follows. In a test that is passed, i.e., zero failures occur, the probability is $100 \%:$ that the component failure-rate does not exceed $\left(k \lambda_{0}\right)$. Here $(1 \cdot \gamma)$ will be referred to as the posterior risk and $\gamma$ will be referred to as the posterior assurance. The word "posterior" denotes that the assurance pertains to tests which have been passed. Of course, values of $\gamma$ and $k$ are required in order to determine the required test plan. More will be said about the selection of these values later.

Recall that the test procedure requires that $n$ items be placed on life test for $t$ hours. If no failures occur, the test is passed. Now, if the test is passed, it may be claimed that a failure-rate not exceeding $\left(k \lambda_{0}\right)$ has been demonstrated with $100 \gamma_{0}^{\circ}$ posterior assurance. If a single failure occurs, the test is failed, and the foregoing claim cannot be made.

The BAZE procedure described requires specification of values for the following five quantities:
- $\lambda_{0}$ (the specified failure-rate)
- a (the prior shape parameter)
- b (the prior scale parameter) 
- $\gamma$ (the pusterior assurance)

- $k$ : the discrimination ratio).

The procedure is developed by writing

$$
\begin{aligned}
p\left(\lambda \leq \lambda^{*} \mid 0 \text { failures }\right) & =\int_{0}^{\lambda *} \frac{(b+n t)^{a}}{\Gamma(a)} \lambda^{a-1} e^{-(b+n t) \lambda} d \lambda \\
& =\frac{I\left(a_{2}[b+n t] \lambda^{*}\right)}{\Gamma(a)},
\end{aligned}
$$

where $I(a, x)$ is the widely studied incomplete gasuma function defined by

$$
I(a, x)=\int_{0}^{x} y^{a-1} e^{-y} d y .
$$

Tables ard computer routines for evaluating this function are widely available for use in our development. Hence, when $\lambda_{\hat{v}}, a, b$, $\gamma$, and $k$ are specified, the three-step procedure for obtaining the required BAZE test $\mathrm{p} 1 \mathrm{an}$ is as follows:

Step 1. Obtain the value of $\theta_{Y}$ from Table Al (in the APPENDIX) for the given values of a and $\gamma$. Note: Table Al may be used directly for $a=0.0001(0.0001) 0.01$ $(0.001) 0.10(0.01) 1.0(0.1) 5.0(0.5) 10.0(1.0)$ 50.0 and $\gamma=0.99, .975, .95, .90, .85, .80, .75$, $.70, . t), .50$. For other values of a and/or $\gamma$, either interpolate in Table Al or solve the equation given by

$$
\int_{0}^{\theta} \gamma_{\lambda} a^{a-1} e^{-\lambda} d \lambda-\gamma \Gamma(a)=0
$$

for $\theta_{\gamma}$. It is mentioned here that in constructing Table Al the incomplete gamma function in the above equation was numerically calculated by use of the code INCGAM, written by D. E. Amos and S. L. Daniel of Sandia Laboratories, Albuquerque, NM, November 1974. The above equation was solved on a CDC 6600 computer by use of the root-solving code ZEROIN, written by L. F. Shampine and H. A. Watts, also of 
Sandia Laboratories, September 1970.

Step 2. With the $\theta_{\gamma}$ value obtained in siep 1 solve for the required BAZE unit-hours of test $(n t)_{0}$ given by

$$
(\mathrm{nt})_{0}=\left(\theta_{\gamma}-\mathrm{bk} \lambda_{0}\right) /\left(\mathrm{k} \lambda_{0}\right) \text {. }
$$

Note: Negative values of (nt) 0 can occur. A negative value of $(n t)_{0}$ can be interpreted as a demonstration of the failure-rate $\left(k \lambda_{0}\right)$, at the stated assurance level, without the need for further testing. This situation occurs whenever the prior distribution satisfactorily meets the assurance reouirement.

Step 3. The required test duration $t_{0}$ and numier of test units $n_{0}$ is given by any pair of values satisfying $n_{0} t_{0}=(n t)_{0}$, where $(n t)_{0}$ is the required unit-hours of test from step 2 and $n_{0}$ is a positive integer. The values $n_{0}$ and $t_{0}$ are selected by outside considerations, such as test time constraints and the number of test units available.

It is noted here that if $a=1, b=0$, and $\gamma=0.50$, then the BAZE test plan is exactly the same as the classical test plan. If $a=1$ and $\gamma=0.50$, then the BAZE test plan will always require less unit-hours of testing, depending upon the magnitude of $b$. For a specified fixed value of a, the required BAZE unit-hours of test decreases as $\gamma$ decreases, $b$ increases, or $k$ increases. Consequently, for given values of $a$ and $b$, an spportunity is present for the test designer to trade between decreasing testing costs [decreasing $(n t)_{0}$ ] and decreasing test assurance [decreasing $\gamma$ and/or increasing $k$ ]. Such tradeoffs are illustrated in Section v.

Suppose that high-reliability components with failure-rate on the order of magnitude of $10^{-6}$ failures/hr. are being considered. If the prior mean is in this range, then it is true that a's the prior variance increases both $a$ and $b$ will generally decrease. In fact, in situations such as this, a will frequently be less than one. This situation occurs whenever the prior variance is quite 
large, i.e., whenever the priur distribution is diffuse [see Waller and Martz (1975)]. Such situations frequently occur in reliability and this fact has motivated the fine grid of a values less than one considered in Table Al.

A quantity of particular interest to the producer or contractor is the uncondicional probability of passing the test when using a test plan with (nt) unit-hours of test. This probability must be sufficiently large in order that the contractor be willing to conduct the test. This probability also conveys to the consumer the likelihood that the required posterior assurance will be realized. This probability is given by

$P$ (Passing the Test $) \equiv P(0$ failures $)=[b /(b+n t)]^{a}$.

Related to this quantity is the conditional probability of passing the test when it is known that the true (unknown) failurerate $\lambda$ lies within a given interval $\left[\lambda_{*}, \lambda^{*}\right]$, where $0 \leq \lambda_{*}<\lambda^{*} \leq \infty$. In this case we have

"(Passing the Test $\left.\mid \lambda_{*} \leq \lambda \leq \lambda{ }^{*}\right)=$

$$
\left(\frac{b}{b+n t}\right)^{a}\left\{\frac{\left.I\left(a,\left[r_{2} t+b\right)\right] \lambda^{*}\right)-I\left(a,[n t+b] \lambda_{*}\right)}{I\left(a, b \lambda^{*}\right)-I\left(a, b \lambda_{*}\right)}\right\} \text {, }
$$

where $I(a, x)$ is defined in (7). It is also noted that, if $\lambda_{*}=0$ and $\lambda^{*}=\infty$, then the conditional probability of passing the test given in (9) reduces to the unconditional probability given in (8). In practice, an interval $\left[\lambda_{*}, \lambda^{*}\right]$ which is certain to rontain the failure-rate can frequently be identified. If this can be done, then (9) should be used in place of (8).

What posterior assurance do we have about the failure-rate if one or more failures occur during the test, i.e., if the test is failed? Suppose that failed items are replaced as they occur during the test. Then

$$
p(x \text { failures } \mid \lambda)=\frac{e^{-n t \lambda}(n t \lambda)^{x}}{x !}, x=0,1, \ldots
$$

and the posterior probability density function of $\lambda$ becomes

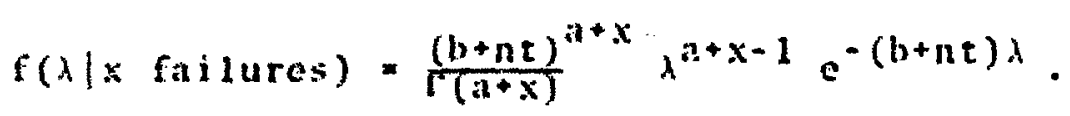


Now, for any specified interval $\left[\lambda_{*}, \lambda^{*}\right]$, where $0 \leq \lambda_{*}<\lambda^{*} \leq \infty$, we have $P\left(\lambda_{*} \leq \lambda \leq \lambda * \mid x\right.$ failures $)=$

$$
\frac{1}{\Gamma(a+x)}\left\{I\left(a+x,[b+n t] \lambda^{*}\right)-I\left(a+x,[b+n t] \lambda_{*}\right)\right\} \text {. }
$$

In particular, we have

$$
P\left(\lambda \leq k \lambda_{0} \mid x \text { failures }\right)=I\left(a+x,[b+n t] k \lambda_{0}\right) / P(a+x) \text {. }
$$

It is observed that, if $x=0$, then (1.j) is equal to the specified posterior assurance $\gamma$. For the criterion failure-rate $\left(k \lambda_{0}\right)$, as $\boldsymbol{x}$ increases (13) becomes smaller than $\gamma$. Thus, as more failures occur, we have less posterior assurance about the failure-rate not exceeding the criterion value.

Also, the unconditional probability of obtaining exactly $x$ failures in a test of nt unit-hours duration is

$$
P(x \text { failures })=\frac{b^{a}(n t)^{x} \Gamma(a+x)}{\Gamma(a) \Gamma(x+1)(n t+b)^{a+x}} \text {. }
$$

The statistical performance characteristics of the chosei plan are completely summarized by means of the posterior operating characteristic (POC) curve. This curve is obtained by plotting $P\left(\lambda \leq \lambda^{*}\right.$ 10 failures) as a function of $\lambda^{*}$. Unlike classical oc curves, the POC curve is a cumulative distribution function. This probability may be computed from (6).

\section{Examp 1e:}

Let us illustrate the foregoing BAZE procedure and associated probabilities by means of an example. Suppose that it is required to obtain the BAZE test plan that demonstrates a component failure-rate of $2.0 \times 10^{-6}$ failure/hr. with $70 \%$ posterior assurance. From prior experience and engineering judgement, the prior gamma distribution mean and standard deviation are both thought to be $1.67 \times 10^{-6}$ failures/hr. Thus $a=1.0$ and $b=0.60 \times 10^{6} \mathrm{hr}$. Now $\left(k \lambda_{0}\right)=2.0 \times 10^{-6}$ failures $/ \mathrm{hr}$. and from Table $A 1$, for $a=1.0$ and $\gamma=0.70$, we find $\theta_{0.70}=1.203973$. The BAZE test plan thus requires $(n t)_{0}=\left[1.203973-\left(0.60 \times 10^{6}\right)\left(2.0 \times 10^{-6}\right)\right] /(2.0 \times 10)^{-6}=$ 1987 unit-hours of testing without any failures in order to 
verify a failure-rate of $2.0 \times 10^{-6}$ or less with $70 \%$ assurance.

The unconditional probabiluty of passing this test is calculated from (8) as

P(Passing the Test $)=\left[\left(0.60 \times 10^{6}\right) /\left(0.60 \times 10^{6}+1987\right)\right]=$ 0.9967.

Suppose that it is known before the test that $\lambda$ lies in the interval $\left(1.0 \times 10^{-7}, 3.0 \times 10^{-5}\right)$. Thus $\lambda_{*}=1.0 \times 10^{-7}$, and $\lambda^{*}=$ $3.0 \times 10^{-5}$. The conditional probability of passing the test from (9) now becomes

P(Passing the Test $1.0 \times 10^{-7} \leq \lambda \leq 3.0 \times 10^{-5}$ )

$$
\begin{aligned}
& =\left(\frac{0.60 \times 10^{6}}{0.60 \times 10^{6}+1987}\right)^{1.0}\left\{\frac{I(1.0,18.0596)-I(1.0,0.0602)}{I(1.0,18)-I(1.0,0.06)}\right\} \\
& =0.9965 .
\end{aligned}
$$

The probability of a single failure in 1987 unit-hours of test is $P(1$ failure $)=\frac{\left(0.10 \times 10^{6}\right)^{1.0}(1987)^{1} \Gamma(2.0)}{\Gamma(1.0) \Gamma(2)\left(1987+0.60 \times 10^{6}\right)^{2.0}}=0.00329$.

The POC curve for this plan is plotted in Figure 1.

It is important to examine the sensitivity of the optimal test plan to changes in the criterion failure-rate ar.d posterior risk. Suppose we let $\lambda_{0}=2.0 \times 10^{-6}$. In Table I we have given the required test plan as a function of a selected grid of values of $k$ and $\gamma$. The plan (nt) $0=1987$ is indicated in the table for $k=1.0$ and $\gamma=0.70$. It is clearly observed that the required unit-hours of test increase as $\gamma$ increases and $k$ decreases. It is observed that the optimal test plan is quite sensitive to increasing $\gamma$ and also somewhat sensitive to decreasing $k$, for the range of $\mathrm{k}$ indicated. The "zeros" indicate those situations in which no testing is required, i.e., the prior distribution is sufficient to guarantee that the risk is at or below the specified level. Table II gives the unconditional probability of passing the corresponding test given in Table $I$. Again, the probability of passing the test when $(n t)_{0}=1987$ is indicated in Table II. In 


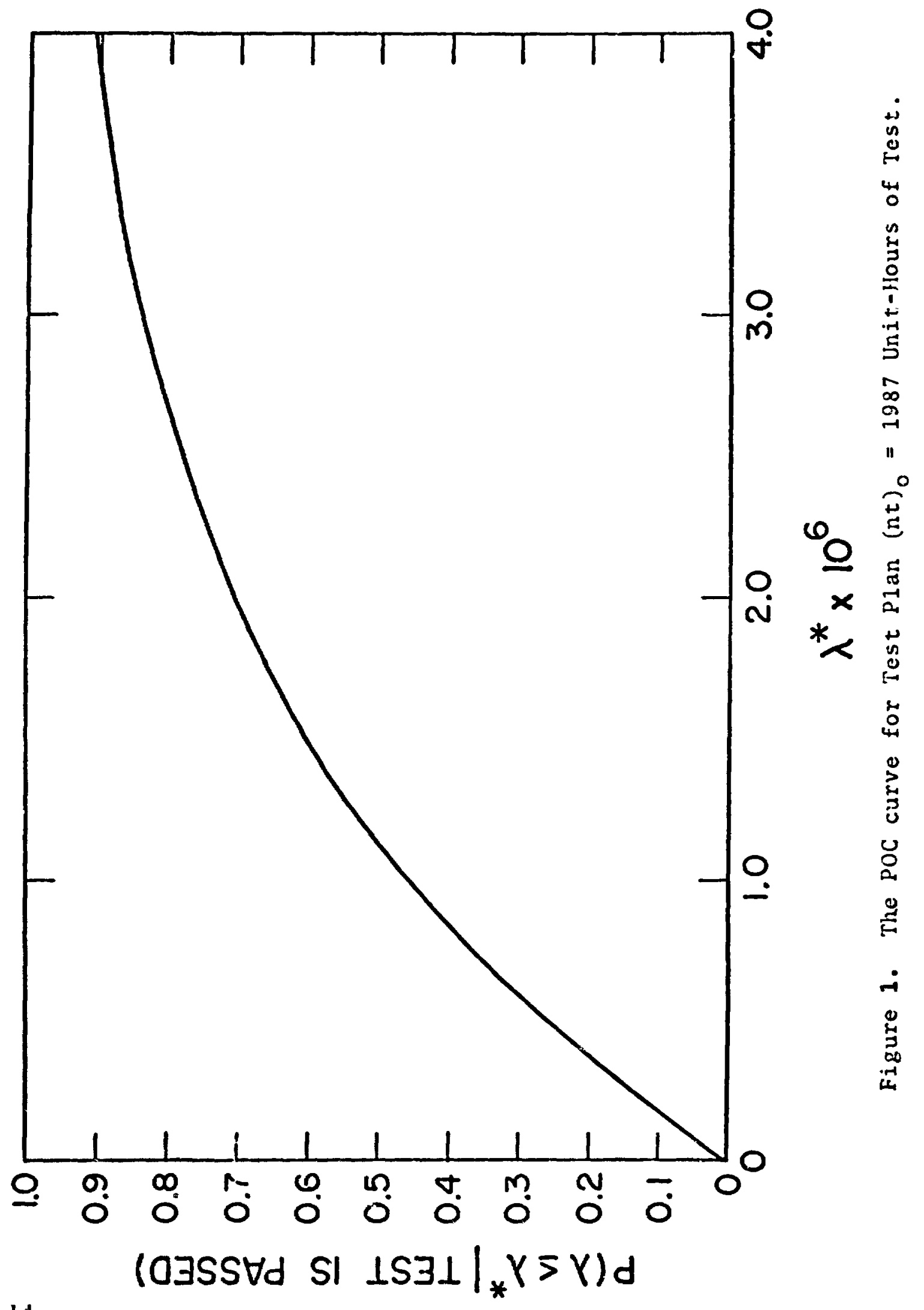


TABLE I

REQUIRLD UNIT-HOURS OF TESTISC FOR

SELECTED VALUES OF $K$ AND $\gamma$

\begin{tabular}{|c|c|c|c|c|c|c|c|c|c|c|c|}
\hline & \multicolumn{11}{|c|}{$k$} \\
\hline & .5 & .6 & .7 & .0 & .9 & i.o & 1.1 & 1.2 & 1.3 & 1.4 & 1.5 \\
\hline $\begin{array}{l}.990 \\
.875 \\
850 \\
.905 \\
.850 \\
.000 \\
750 \\
7900 \\
.600 \\
.500\end{array}$ & 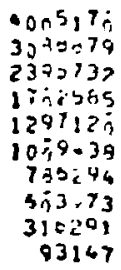 & $\begin{array}{r}3237662 \\
2614036 \\
1675663 \\
1314721 \\
989733 \\
161196 \\
555265 \\
403311 \\
163576\end{array}$ & $\begin{array}{r}2697407 \\
2436416 \\
15340.19 \\
1046704 \\
755046 \\
569540 \\
370210 \\
250481 \\
54694 \\
6\end{array}$ & $\begin{array}{r}2774231 \\
1 / n 5564 \\
1272333 \\
034110 \\
555700 \\
405894 \\
266434 \\
152403 \\
0\end{array}$ & $\begin{array}{r}1053429 \\
166737 \\
1000275 \\
677216 \\
153476 \\
28613 ? \\
170163 \\
62074 \\
0\end{array}$ & $\begin{array}{r}1702535 \\
12054-10 \\
007036 \\
551293 \\
365500 \\
204717 \\
03167 \\
\frac{1807}{0}\end{array}$ & $\begin{array}{r}1453250 \\
2074763 \\
76,600 \\
44,030 \\
202337 \\
13,533 \\
30134 \\
0 \\
0\end{array}$ & $\begin{array}{r}1319021 \\
137033 \\
0-6222 \\
159610 \\
190057 \\
70599 \\
0 \\
0\end{array}$ & $\begin{array}{r}1131210 \\
y 13500 \\
532205 \\
262011 \\
12003 \\
17025 \\
0\end{array}$ & $\begin{array}{r}204+706 \\
717-57 \\
45930 \\
22235 ? \\
17543 \\
0 \\
0 \\
0\end{array}$ & $\begin{array}{r}2.75257 \\
529525 \\
350278 \\
167503 \\
3<173 \\
0 \\
0\end{array}$ \\
\hline
\end{tabular}

TABLE II

THE UNCONDITIONAL PROBABILITIES OF PASSINC THE COREESPOSDIXG TESTS IA TABLE I

\begin{tabular}{|c|c|c|c|c|c|c|c|c|c|c|c|}
\hline$y$ & .5 & .6 & .7 & .8 & .9 & 1.0 & 1.1 & 1.2 & 1.3 & 1.4 & 1.5 \\
\hline $\begin{array}{l}.990 \\
.975 \\
.950 \\
.900 \\
.850 \\
.800 \\
.750 \\
.700 \\
.600 \\
.500\end{array}$ & $\begin{array}{l}.139 \\
.163 \\
.200 \\
.201 \\
.310 \\
.373 \\
.433 \\
.494 \\
.655 \\
.065\end{array}$ & $\begin{array}{r}.156 \\
.195 \\
.240 \\
.313 \\
.330 \\
.447 \\
.519 \\
.598 \\
.786 \\
1.000\end{array}$ & $\begin{array}{l}.182 \\
.228 \\
.280 \\
.365 \\
.243 \\
.522 \\
.606 \\
.698 \\
.917 \\
1.000\end{array}$ & $\begin{array}{r}.208 \\
.260 \\
.320 \\
.417 \\
.506 \\
.570 \\
.692 \\
.797 \\
1.000 \\
1.000\end{array}$ & $\begin{array}{l}.235 \\
.293 \\
.361 \\
.469 \\
.559 \\
.07 .1 \\
.179 \\
.097 \\
1.000 \\
1.000\end{array}$ & $\begin{array}{r}.201 \\
.325 \\
.401 \\
.521 \\
.633 \\
.746 \\
.805 \\
1.00 \\
1.000\end{array}$ & $\begin{array}{r}.237 \\
.358 \\
.441 \\
.573 \\
.536 \\
.920 \\
.952 \\
1.030 \\
1.003 \\
1.000\end{array}$ & $\begin{array}{r}.313 \\
.370 \\
.491 \\
.625 \\
.759 \\
.875 \\
1.000 \\
1.000 \\
1.000 \\
1.1000\end{array}$ & $\begin{array}{l}.339 \\
.423 \\
.521 \\
.677 \\
.822 \\
.939 \\
1.000 \\
1.000 \\
1.000 \\
1.000\end{array}$ & $\begin{array}{r}.365 \\
.455 \\
.561 \\
.730 \\
.856 \\
1.000 \\
1.000 \\
1.000 \\
1.000 \\
1.000\end{array}$ & $\begin{array}{r}.341 \\
.080 \\
.641 \\
.752 \\
.507 \\
1.000 \\
1.000 \\
1.200 \\
1.000 \\
1.000\end{array}$ \\
\hline
\end{tabular}


TABLE III

RANKINE POWER CONVERSION SYSTEM RELIABILITY PROJECTION

\begin{tabular}{|c|c|c|c|c|c|}
\hline \multirow{2}{*}{ COMPONENT } & \multicolumn{3}{|c|}{ GENERIC FAILLRE RATES 1,2} & \multicolumn{2}{|c|}{ PROJICTED PCS GENERIC FAILUME RATE } \\
\hline & LOWER LIMIT & MEAN & UPPER LIMIT & OPERAT ING & STARTING \\
\hline ACCUMULATOR & 0.35 & 7.2 & 19.3 & -- & 0.35 \\
\hline START VALVE (SOLENOID) & 1.87 & 4.6 & 7.41 & 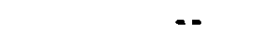 & 1.87 \\
\hline JET PUMP & 0.01 & 0.15 & 2.11 & $0.0 i$ & \\
\hline START PUMP (MOTOR) & 2.25 & 8.7 & 27.4 & -- & 2.25 \\
\hline HIGH-PKESSURE PUMP & 1.12 & 8.74 & 31.3 & 1.12 & \\
\hline RADIATOR & 2.21 & 5.0 & 12.5 & 0.81 & \\
\hline THERMAL BY-PASS VALVE & 0.24 & 1.9 & 2.2 & 0.24 & \\
\hline RADIATOR FILTER & 0.011 & 0.3 & 1.8 & 0.01 & \\
\hline JET CONDENSOR & -- & -- & $\cdots$ & 0.50 & \\
\hline WICK SCAVENGE JET PUMP & 0.01 & 0.15 & 2.11 & 0.01 & \\
\hline FLOW LIMITER VALVE & 0.24 & 1.9 & 2.2 & 0.24 & \\
\hline FLOW CONTROL VALVE & 0.24 & 1.9 & 2.2 & 0.24 & \\
\hline TURBINE ASSEMBLY & 3.33 & 10.9 & 16.67 & 1.0 & \\
\hline ALTERNATOR & 0.033 & 0.7 & 2.94 & 0.7 & \\
\hline REGENERATOR & 1.0 & 4.4 & 19.6 & 0.5 & \\
\hline REGENERATOR BY-PASS VALVE & 0.224 & 3.92 & 32.5 & 0.22 & \\
\hline BOILER & 1.0 & 4.4 & 19.6 & 0.5 & \\
\hline SCREEN FILTER & 0.011 & 0.3 & 1.8 & 0.01 & \\
\hline ELECTRUNIC CONTROL UNIT & -- & $\cdots$ & $\cdots$ & 0.36 & \\
\hline
\end{tabular}

$1\left(X 10^{-6} / \mathrm{HR}.\right)$.

${ }^{2}$ Failure rates are from Avco Corp. "Reliability Engineering Data Series." 
practice, tables like Tables I and I I should be constructed and used by both consume; and producer to select the final test plan. We cannot emphasize enough that both the consumer and producer must be willing to pay the price for increasing assurance of small failure-rates by increasing the unit-hours of testing. For illustration we note that verification of small failure-rates with even reasonable cunfidence requires a large amount of testing. The next section builds on the preceding general discussion to address the problem of selecting a prior distribution with application to a particular hardware system.

IV. PRIOR DISTRIBUTIONS FITTED TO COMPONENTS OF A PROPOSED RANKINE POWER CONVERSION SYSTEM

The first step in determining the BAZE test plan for a given system is to identify a prior distribution for the failure-rate. Our source of prior failure-rate information is Proposal No. 2911AP1, RFQ No. SNS-75-2-CAO "Kilowatt Isotopes Power System" prepared by suinstrand linergy Systems. In particular Table 4.4-B of that document, as reproduced in Table III, provides component failurerates for the power conversion system ( $P C S$ ) of the proposed Rankine system. We use the generic failure-rate data in Table II to fit a gamma prior distribution to each appropriate component of the proposed Rankine system.

The gamma prior probability density function (pdf) is given by

$$
f(\lambda)=\frac{b^{a}}{\Gamma(a)^{\lambda-1}} c^{-b \lambda}, \lambda \geq 0, a>0, b>0,
$$

where the shape and scale parameters, $a$ and $b$, are determined from the data in rable III. The mean and variance of the gamma distribution above are given by $(a / b)$ and $\left(a / b^{2}\right)$, respectively. It will be assumed here that the spread between the upper and lower 1 imits in Table III represents a certain assumed number of standard deviations of the gamma pdf. The means Iisted in Table III will be tikken to be the prior means. Table IV gives the prior mean, prior variance, shape parameter a, and scale parameter $b$ for the appropriate components in the PCS. The jet condenser and electronic 
control unit are not considered in Table IV due to the absence of prior information on these components. Classical reliability demonstration test plans should be used for these components. The prior variance is calculated from the expression

$$
\text { Prior Variance }=\left(\frac{\text { UPPER LIMIT }- \text { LOWER LIMIT }}{m}\right)^{2} \text {, }
$$

where $m>0$ is a constant chosen to reflect the prior confidence that the range (lower limit, upper limit) contains the true failure-rate. There are no rigid rules for selecting a value of $\mathrm{m}$. However, engineering judgement and statistical analysis can be used in determining a suitable value. To assist in selecting $\mathrm{m}$, the following arbitrary rules of thumb are suggested. These rules were used bere to select the values of $m$ appearing in Table IV.

Rule 1. If the specified failure-rate (SFR) $\lambda_{0}$ is well within the range of the generic failure-rate, $m$ is taken to be 3 . (This yields a somewhat concentrated prior distribution with a relatively small prior probability that the true failure-rate lies outside the given range.)

Rule 2. If the SFR $\lambda_{0}$ is ciose to either the lower or upper limits of the generic failure-rate, $m$ is taken to be 2. (This yields a diffuse prior distribution. with a rather large prior probability that the true failure-rate lies outside the given range.)

Rule 3. If the SFR $\lambda_{0}$ is well below the lower limit of the generic failure-rate, $m$ is taken to be 1 . (This yields an extremely diffuse prior distribution with a large prior probability that the true failure-rate lies outside the given range.)

The more diffuse the prior distribution, the less precise the prior information concerning the failure-rate. In fact, for the situation described in Rule 3 above, it may be inappropriate to consider prior information at all, due to the projected differences in the reliability of the current component compared to previous components. These differences are due to technological advances. In such a case, a Bayesian verification test procedure may be less desirable than a purely classical procedure which does not utilize prior information. 
TABLE IV

GAMMA PRIOR DISTRIBUTIONS FOR THE COMPONENTS IN THE PROPOSED RANKINE PCS

\begin{tabular}{|c|c|c|c|c|c|c|c|c|c|}
\hline \multirow[b]{2}{*}{ COMPONENT } & \multicolumn{3}{|c|}{ GENERIC FAILURE RATES } & \multirow{2}{*}{$\lambda_{0}{ }^{1}$} & \multirow{2}{*}{$\begin{array}{l}\text { PRIOR } \\
\text { MEAN }^{1}\end{array}$} & \multirow{2}{*}{$\mathbf{m}$} & \multirow{2}{*}{$\begin{array}{c}\text { PRIOR } \\
\text { VARIANCE }^{2}\end{array}$} & \multirow{2}{*}{$\mathbf{a}$} & \multirow{2}{*}{$b^{3}$} \\
\hline & $\begin{array}{l}\text { LOWER } \\
\text { LIMIT }\end{array}$ & MEA. & $\begin{array}{l}\text { UPPER } \\
\text { LIMIT }\end{array}$ & & & & & & \\
\hline ACCUMULATOR & 0.35 & 7.2 & 19.3 & 0.35 & 7.2 & 2 & 89.78 & 0.58 & 8.02 \\
\hline START VALVE & 1.87 & 4.6 & 7.41 & 1.87 & 4.6 & 2 & 7.67 & 2.80 & 60.87 \\
\hline $\begin{array}{l}\text { JET PUMP; WICK } \\
\text { SCAVENGER JET } \\
\text { PUMP }\end{array}$ & 0.01 & 0.15 & 2.11 & 0.01 & 0.15 & 2 & 1.10 & 0.02 & 13.64 \\
\hline START PUMP (MOTOR) & 2.25 & 8.7 & 27.4 & 2.25 & 8.7 & 2 & $158.1 \overline{1}$ & 0.48 & 5.50 \\
\hline HIGH-PRESSURE PUMP & 1.12 & 8.74 & 31.3 & 1.12 & 8.74 & 2 & 227.71 & 0.34 & 3.84 \\
\hline RADIATOR & 2.21 & 5.0 & 12.5 & 0.81 & 5.0 & 1 & 105.88 & 0.24 & 4.72 \\
\hline $\begin{array}{l}\text { THERMAL BY - PASS } \\
\text { VALVE; FLOW } \\
\text { LIMITER VALVE; } \\
\text { FLOW CONTROL VALVE }\end{array}$ & 0.24 & 1.9 & 2.2 & 0.24 & 1.9 & 2 & 0.96 & 3.80 & 200.00 \\
\hline $\begin{array}{l}\text { RADIATOR FILTER; } \\
\text { SCREEN FILTER }\end{array}$ & 0.011 & 0.3 & 1.8 & 0.01 & 0.3 & 2 & 0.80 & 0.11 & 37.50 \\
\hline TURBINE ASSEMBLY & 3.33 & 10.9 & 16.67 & 1.0 & 10.9 & 1 & 177.96 & 0.67 & 6.12 \\
\hline ALTERNATOR & 0.033 & 0.7 & 2.94 & 0.7 & 0.7 & 3 & 0.94 & 0.52 & 74.47 \\
\hline $\begin{array}{l}\text { REGENERATOR; } \\
\text { BOI LER }\end{array}$ & 1.0 & 4.4 & 19.6 & 0.5 & 4.4 & 1 & 345.96 & 0.05 & 1.27 \\
\hline $\begin{array}{l}\text { REGENERATOR BY-PASS } \\
\text { VALVE }\end{array}$ & 0.224 & 3.92 & 32.5 & 0.22 & 3.92 & 2 & 260.44 & 0.05 & 1.51 \\
\hline
\end{tabular}

${ }^{1}\left(X 10^{-6} / \mathrm{HR}.\right){ }^{2}\left(\mathrm{X10}^{-12} / \mathrm{HR}^{2}\right) .{ }^{3}\left(X 10^{4} \mathrm{HR}.\right)$ 
The parameters $a$ and $b$ in Table IV are calculated by means of the expressions

$a=(\text { Prior Mean })^{2} /$ Prior Variance

and

$\mathrm{b}=\mathrm{a} /$ Prior Mean.

Table $\mathrm{V}$ presents certain quantities of interest associated with the fitted gamma prior distributions in Table IV. The quantities $\mathrm{P}_{1}, \mathrm{P}_{2}, \mathrm{P}_{3}$, and $\mathrm{P}_{4}$ in $\mathrm{T}$ able $\mathrm{V}$ represent the probabilities defined by

$$
\begin{aligned}
& \mathrm{P}_{1} \equiv \text { Prob. }(\lambda \leq \text { Prior Mean }), \\
& \mathrm{P}_{2} \equiv \operatorname{Prob} .\left(\lambda \leq \lambda_{0}\right), \\
& \mathrm{P}_{3} \equiv \operatorname{Prob} .(\lambda \leq \text { Lower Limit }), \\
& \mathrm{P}_{4} \equiv \operatorname{Prob.}(\lambda \equiv \text { Upper Limit }) .
\end{aligned}
$$

Thus $\left(\mathrm{P}_{3}+\mathrm{P}_{4}\right)$ represents the prior probability that the generic interval given in Table IV does not contain the true failure-rate. The probabilities in (19) are calculated by means of the incomplete gamma function code, INCGAM, mentioned in section III.

It is observed that the probabilities labeled $\mathrm{P}_{2}$ in Table $\mathrm{V}$ range from 0.002 to 0.89 , with an average of 0.45 . Such values represent a somewhat pessimistic prior view towards the projected component reliability of the KIPS PCS. Such a view is typically taken by a consumer. These values are the result of the specified component failure-rates being near or below the lower Iimit of the generic failure-rate range of the handbook values as reported in Table III. The direct effect of these $P_{2}$ values is an increase in the number of unit-hours of demonstration testing required. This is a reasonable conclusion supportive of the pessimistic view that, if a component failure-rate is projected to be towards the lower limit of the generic interval, correspondingly increased testing should be performed to support such a low projection.

The values of $\left(\mathrm{P}_{3}+\mathrm{P}_{4}\right)$ in Table $\mathrm{V}$ range from 0.20 to 0.91 with an average of 0.54 . For those components whose projected failure-rate lies at or below the lower limit of the historical generic interval, $\left(\mathrm{P}_{3}+\mathrm{P}_{4}\right)$ is correspondingly 1arge. This represents an optimistic point of view favoring the producer. 
TABLE V

ANALYSIS OF THE GAMAA PRIOR DISTRIBUTIONS FOR THE COMPONENTS IN THE PROPOSED RANKINE PCS

\begin{tabular}{|c|c|c|c|c|c|c|c|c|c|}
\hline \multirow[b]{2}{*}{ COMPONENT } & \multicolumn{2}{|c|}{ GAMMLA PARANUETERS } & \multirow{2}{*}{$\begin{array}{l}\text { PRIOR } \\
\text { MEAN }\end{array}$} & \multirow{2}{*}{$\begin{array}{c}\text { PRIOR } \\
\text { VARIANCE }\end{array}$} & \multirow{2}{*}{$P_{1}$} & \multirow{2}{*}{$\mathbf{P}_{2}$} & \multirow{2}{*}{$\mathrm{F}_{3}$} & \multirow{2}{*}{$P_{4}$} & \multirow{2}{*}{$\mathrm{P}_{3}+\mathrm{P}_{4}$} \\
\hline & $a$ & $b^{3}$ & & & & & & & \\
\hline ACCURULATOR & 0.58 & 8.02 & 7.2 & 89.78 & 0.67 & 0.14 & 0.14 & 0.10 & 0.24 \\
\hline START VALVE & 2.80 & 60.87 & $4.6^{-}$ & 7.67 & .58 & .14 & .14 & .14 & .28 \\
\hline $\begin{array}{l}\text { JET PUMP ; WICK } \\
\text { SCAVENGER JET } \\
\text { PUMP }\end{array}$ & 0.02 & 13.64 & 0.15 & 1.10 & .94 & .89 & .89 & .02 & .91 \\
\hline START PUR.SP (MOTOR) & 0.48 & 5.50 & 8.7 & 158.13 & .69 & .40 & .40 & .08 & .48 \\
\hline HI GH-PRESSURE PUMP & 0.34 & 3.84 & 8.74 & 227.71 & .71 & .38 & .38 & .07 & .45 \\
\hline RADIATOR & 0.24 & 4.72 & 5.0 & 105,88 & .74 & .50 & .63 & .13 & .76 \\
\hline $\begin{array}{l}\text { THERMAL BY-PASS } \\
\text { VALVE; FLOW } \\
\text { LIMITER VALVE; } \\
\text { FLOW CONTROL VALVE }\end{array}$ & 3.8 & 200.00 & 1.9 & 0.96 & .57 & .002 & .002 & .32 & .32 \\
\hline $\begin{array}{l}\text { RADIATOR FILTER; } \\
\text { SCREEN FILTER }\end{array}$ & 0.11 & 37.50 & 0.3 & 0.80 & .82 & .57 & .58 & .05 & .63 \\
\hline TURBINE ASSEMBLY & 0.67 & 6.12 & 10.9 & 177.96 & .66 & .17 & .35 & .22 & .57 \\
\hline ALTERNATOR & 0.52 & 74.47 & 0.7 & 0.94 & .68 & .68 & .16 & .04 & .20 \\
\hline $\begin{array}{l}\text { REGENERATOR; } \\
\text { BOILER }\end{array}$ & 0.05 & 1.27 & 4.4 & 345.96 & .89 & .80 & .83 & .05 & .80 \\
\hline $\begin{array}{l}\text { REGENERATOR BY-PASS } \\
\text { VALVE }\end{array}$ & 0.05 & 1.51 & 3.92 & 260.44 & .89 & .77 & .77 & .03 & .80 \\
\hline
\end{tabular}


A1so, it is to be noted that those gamma prior distributions in Table IV for which $a<1.0$ are L-shaped, with an asymptote existing at the ordinate axis.

It is remarked here that these fitted prior distributions represent our suggested choices based on statistical analyses only. Other considerations may be present which have not been included here. These may yield different prior distributions from those given in Table IV.

V. BAZE TEST PLANS FOR COMPONENTS OF A PROPOSED RANKINE POWER CONVERSION SYSTEM

The purpose of this section is to propose a range of possible BAZE test plans for several components in a proposed Rankine PCS. These test plans will be obtained by means of the gamma prior distributions suggested in the preceding section. It is emphasized that the plans given here are not to be considered an exhaustive set or the sole sonrce for the final selection. The final selection should be made by the producer with the consenting agreement of the consumer. It may be necessary or desirable to alter the prior distributions given in Table IV for reasons of which we are unaware at this time. Such alterations will result in different test plans from those proposed here.

To illustrate the BAZE test plan procedure, consider the accumulator of the proposed Rankine PCS. From Table 4, we have the SFR $\lambda_{0}=0.35 \times 10^{-6} \mathrm{f} . / \mathrm{hr}, \mathrm{a}=0.58$, and $\mathrm{b}=8.02 \times 10^{4} \mathrm{hr}$. From Table Al, we have

\begin{tabular}{c|c|c|c|c|c}
$\gamma$ & 0.99 & 0.975 & 0.95 & 0.90 & 0.85 \\
\hline$\theta_{\gamma}$ & 3.550563 & 2.723769 & 2.112674 & 1.519950 & 1.185539 \\
\hline$\gamma$ & 0.80 & 0.75 & 0.70 & 0.60 & 0.50 \\
\hline$\theta_{Y}$ & 0.955969 & 0.783608 & 0.647407 & 0.443461 & 0.297721
\end{tabular}

Table VI presents the required unit-hours of testing for selected values of the discrimination ratio $(k)$ and the posterior assurance 
$(\gamma)$. For example, for $k=20$ and $\gamma=0.75$, it would require (nt) 0 $=\left[0.783608-\left(8.02 \times 10^{4}\right)(20)\left(0.35 \times 10^{-6}\right)\right] /\left[(20)\left(0.35 \times 10^{-6}\right)\right]$ $=31,744$ unit-hours of testing without a failure in order to demonstrate a failurerate $7.0 \times 10^{-6} \mathrm{f} . / \mathrm{hr}$. with $75 \%$ assurance. Thus 10 accumulators could be tested for $3,174 \mathrm{hr}$.; 5 accumulators for $6,349 \mathrm{hr}$., etc. One may question whether a multiple of 20 times the SFR is too large to be meaningful in view of the overall projected system failure-rate requirement which is $6.43 \times 10^{-6} \mathrm{f} / \mathrm{hr}$. For $\mathrm{k}=1$ and $\gamma=0.75$, it would require $2,158,680$ unit-hours of testing. This unreasonable amount of testing is largely due to the fact that the generic failure-rate interval $\left(0.35 \times 10^{-6}, 19.3 \times 10^{-6}\right)$ is extremely large and that the SFR corresponds to the lower end point of this interval. Hence, in order to verify a failure-rate which is significantly smaller than the historical mean $7.2 \times 10^{-6}$ would require an extremely large amount of testing without failures. This is a pessimistic result which places the burden of proof on the producer in the form of increased testing.

Table VII gives the unconditional probabilities of passing the corresponding tests given in Table VI. It is observed that the unconditional probability of passing a test having 31,744 unit-hours of testing is 0.824 .

Tables VIII - XXIX similarly provide a suggested range of test plans and associated unconditional probabilities of passing the corresponding tests for the remaining components in the proposed Rankine pCs.

Again, it is emphasized that these are suggested plans on $1 y$. The final choice of a BAZE component test plan must be made by the producer in cooperation with the consumer.

The selection of BAZE component test plans which adhere to an overall system failure-rate requirement will be considered in the next section.

VI. ADDITIONAL CONSIDERATIONS AND CONCLUSIONS

In this section we consider several additional aspects associated with the BAZE testing procedure. First, we consider the 
TABLE VI

REQUIRED BAZE TEST PLANS FOR THE ACCUMULATOR OF THE PROPOSED RANKINE PCS

\begin{tabular}{|c|c|c|c|c|c|c|c|c|c|c|c|}
\hline 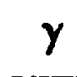 & $10 . i$ & 12.7 & is.n & 16.0 & 79.: & $2 n \cdot 1$ & 20.6 & 24.9 & 26.7 & 29. & 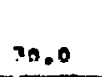 \\
\hline 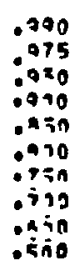 & 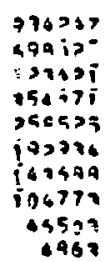 & $\begin{array}{l}745175 \\
508113 \\
62919 \\
291498 \\
292171 \\
147615 \\
196779 \\
73767 \\
25384\end{array}$ & $\begin{array}{r}4166^{\circ 5} \\
175571 \\
156959 \\
277904 \\
141767 \\
116494 \\
73730 \\
51574 \\
16312 \\
0\end{array}$ & $\begin{array}{l}553790 \\
436197 \\
297940 \\
171290 \\
13150^{\circ} \\
91590^{\circ} \\
5977^{\circ} \\
354\end{array}$ & 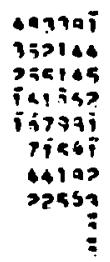 & $\begin{array}{r}427323 \\
329=10 \\
321411 \\
172734 \\
9614.7 \\
34747 \\
31764 \\
12>47\end{array}$ & 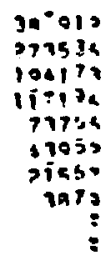 & $\begin{array}{r}302+45 \\
300953 \\
171397 \\
1007+5 \\
00735 \\
32545 \\
13208 \\
9\end{array}$ & $\begin{array}{r}307+73 \\
787115 \\
151+45 \\
45437 \\
53375 \\
2655 ? \\
591 ! \\
5\end{array}$ & 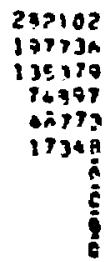 & $\begin{array}{r}257067 \\
170797 \\
191947 \\
46557 \\
17734 \\
10485\end{array}$ \\
\hline
\end{tabular}

TABLE VII

THE UNCONDITIONAL PROBABILITY OF PASSINC THE CORRESPONDING BAEE TESTS IA TABLII VI

\begin{tabular}{|c|c|c|c|c|c|c|c|c|c|c|c|}
\hline$y$ & $i n . i$ & {$[\geq 0$} & 14.7 & ia.t & 19.0 & $2 \pi . \bar{n}$ & $30 . \overline{1}$ & $=4 . n$ & $34 .=$ & $2 a . n$ & $3 n$. \\
\hline $\begin{array}{l}970 \\
.995 \\
.950 \\
.910\end{array}$ & $\begin{array}{l}.291 \\
.729 \\
319 \\
.375\end{array}$ & $\begin{array}{l}.755 \\
.798 \\
.745 \\
.417\end{array}$ & $\begin{array}{r}.277 \\
.325 \\
.377 \\
.454\end{array}$ & $\begin{array}{r}711 \\
.352 \\
697 \\
673\end{array}$ & $\begin{array}{r}.723 \\
.776 \\
.436 \\
.525\end{array}$ & & 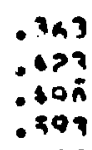 & $\begin{array}{l}.791 \\
.145 \\
.515 \\
.4>0\end{array}$ & 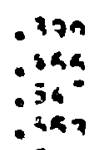 & $\begin{array}{l}.075 \\
\text {-494 } \\
.444 \\
\text {.495 }\end{array}$ & $\because$ \\
\hline 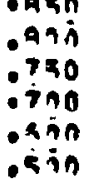 & $\begin{array}{l}0495 \\
.591 \\
.405 \\
.747 \\
.945\end{array}$ & $\begin{array}{r}.546 \\
.513 \\
.695 \\
.853 \\
.700\end{array}$ & $\begin{array}{l}079 \\
.579 \\
979\end{array}$ & & $\begin{array}{r}.791 \\
.775 \\
.946 \\
1.7 n 0 \\
\text { I. ino }\end{array}$ & & $\begin{array}{l}071 \\
971\end{array}$ & & 1.9 & $\begin{array}{l}i . i^{2}=i \\
1.0=i\end{array}$ & $\begin{array}{l}n \\
0 \\
n\end{array}$ \\
\hline
\end{tabular}


TARI.E VIII

REQUIRI:D SAEI: TEST PLANS fOR THE START VALHE

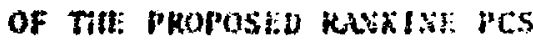

\begin{tabular}{|c|c|c|c|c|c|c|c|c|c|c|c|}
\hline$y$ & 1.5 & 1.4 & 1.3 & 1.0 & i. & 1.5 & 2.1 & 2.2 & 2.3 & 8.6 & 2.5 \\
\hline 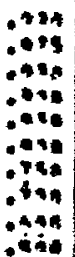 & 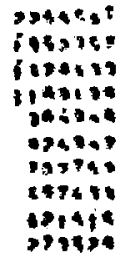 & 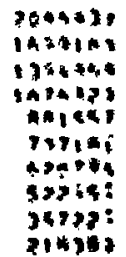 & 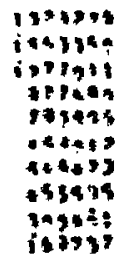 & 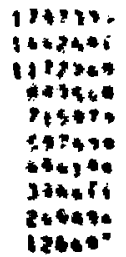 & 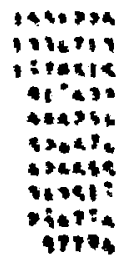 & 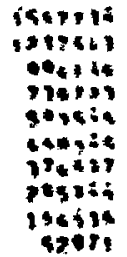 & 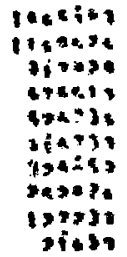 & 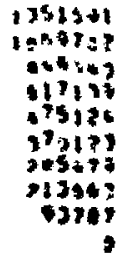 & 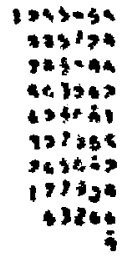 & 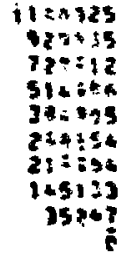 & 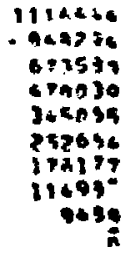 \\
\hline
\end{tabular}

TARLE: IX

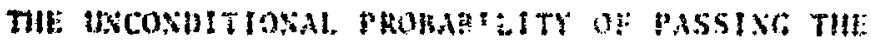

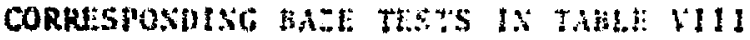

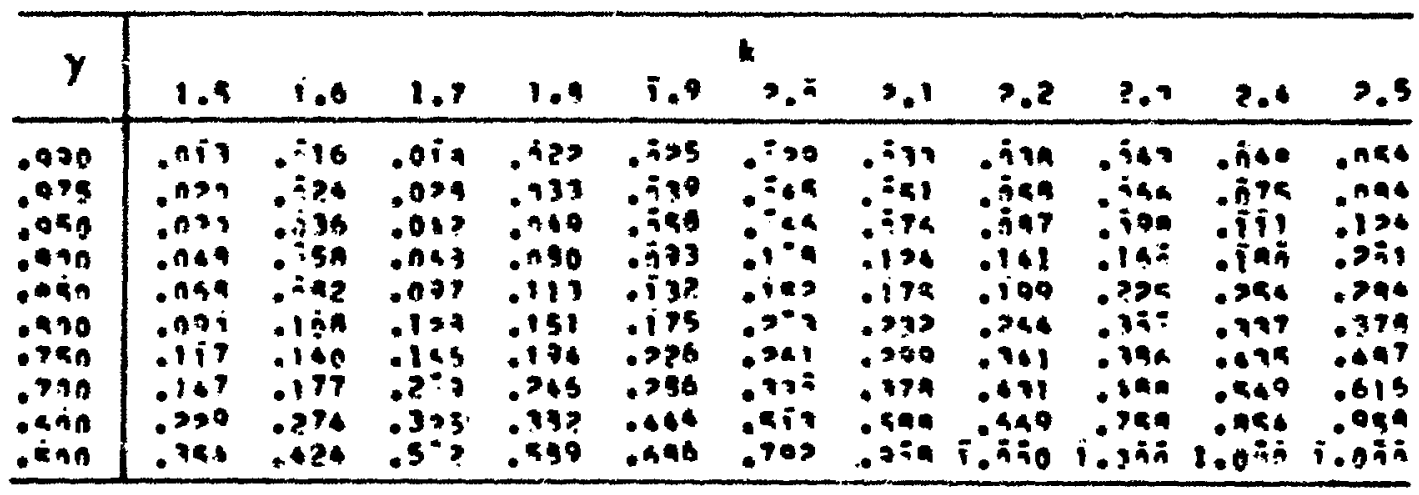


TABLE $X$

REQUIRFD BAZE TEST PLANS FOR THE JET FUMP

AND WICK SCAVENCER JET PUSP OF THE

PROPOSED RANKINE PCS

\begin{tabular}{|c|c|c|c|c|c|c|c|c|c|c|c|}
\hline$y$ & $5 . j$ & 6.8 & 9.0 & 9.0 & 9. & k 1 i. & 17.5 & 12.0 & is.s & 16.7 & 15.0 \\
\hline 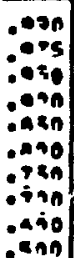 & 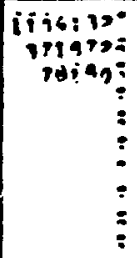 & $\begin{array}{r}917836 ? \\
3076>0 \\
62876 ? \\
\vdots \\
\vdots \\
\vdots \\
\vdots\end{array}$ & 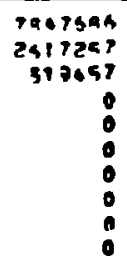 & $\begin{array}{r}684967= \\
227305= \\
43947 \\
\vdots \\
\vdots\end{array}$ & 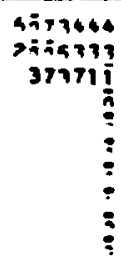 & 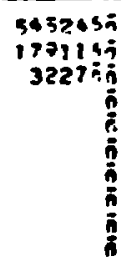 & $\begin{array}{r}4760372 \\
1515027 \\
29059 \\
\vdots \\
\vdots \\
\vdots \\
\vdots\end{array}$ & $\begin{array}{r}4520783 \\
1469700 \\
246183 \\
0 \\
0 \\
\vdots \\
0 \\
0 \\
0\end{array}$ & 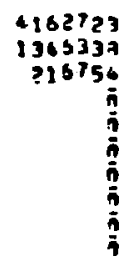 & 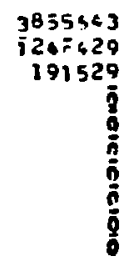 & $\begin{array}{r}3590507 \\
116866= \\
16965 ?\end{array}$ \\
\hline
\end{tabular}

TABLE XI

THE UNCONDITIONAL PROBABILITY OF PASSING THE CORRESPONDING BZIZE TESTS IN TABLE $X$

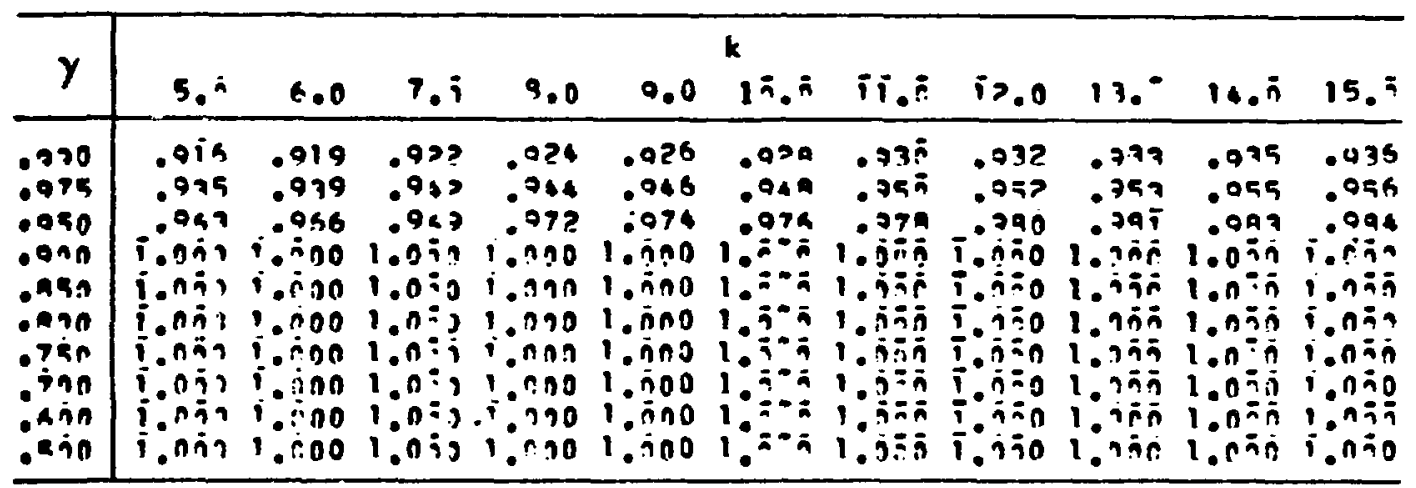


REQUIRED RAZL TEST PLANS FOR THE START PUMP (MOTOR) OF THE PROPOSED RLNINE PCS

\begin{tabular}{|c|c|c|c|c|c|c|c|c|c|c|c|}
\hline & $\supset . \bar{n}$ & $3 . ?$ & $=.4$ & 2.6 & 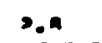 & 3.9 & 1.7 & 3.6 & 3.6 & 3.9 & 0.0 \\
\hline $\begin{array}{l}07 n \\
.975 \\
07 n\end{array}$ & 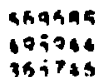 & $\begin{array}{l}102996 \\
41113 \\
32205 i\end{array}$ & $\begin{array}{l}1070>1 \\
707053 \\
29105,5\end{array}$ & $\begin{array}{l}\text { SAlKAi } \\
364947 \\
264 A^{\circ} a\end{array}$ & 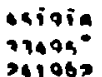 & $\begin{array}{l}42+557 \\
39294 \frac{1}{3} \\
320144\end{array}$ & 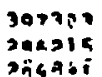 & $\begin{array}{l}370557 \\
206103 \\
109557\end{array}$ & $\begin{array}{l}147067 \\
0: 33=0 \\
75979\end{array}$ & $\begin{array}{l}325947 \\
232339 \\
167934\end{array}$ & $\begin{array}{l}3 n 4069 \\
217915 \\
192019\end{array}$ \\
\hline 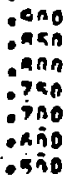 & 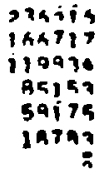 & $\begin{array}{r}292=67 \\
146561 \\
197265 \\
72617 \\
67984 \\
12675\end{array}$ & $\begin{array}{r}197513 \\
197716 \\
0,595 \\
41794 \\
37313 \\
5416 \\
0\end{array}$ & $\begin{array}{l}15 \text { AQSA } \\
11555 \\
79597 \\
5781 \\
32960 \\
175 \%\end{array}$ & $\begin{array}{r}\text { ifonsa } \\
177349 \\
49475 \\
6511 \\
29979 \\
\vdots\end{array}$ & $\begin{array}{r}17911 \\
72911 \\
61356 \\
34034 \\
20 \div 57 \\
\end{array}$ & 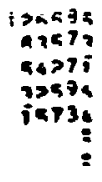 & $\begin{array}{r}16194 \\
75628 \\
67363 \\
27643 \\
1157\end{array}$ & $\begin{array}{r}195075 \\
63174 \\
62134 \\
22967 \\
7075\end{array}$ & $\begin{array}{r}79164 \\
51493 \\
37518 \\
18765 \\
4566 \\
8\end{array}$ & $\begin{array}{r}70549 \\
55850 \\
72417 \\
15077 \\
1598\end{array}$ \\
\hline
\end{tabular}

TABLE XIII

THE UNCONDITIONAL PROBABILITY OF FASSING THE CORRESHONDING BAZE TESTS IN TABLE XII

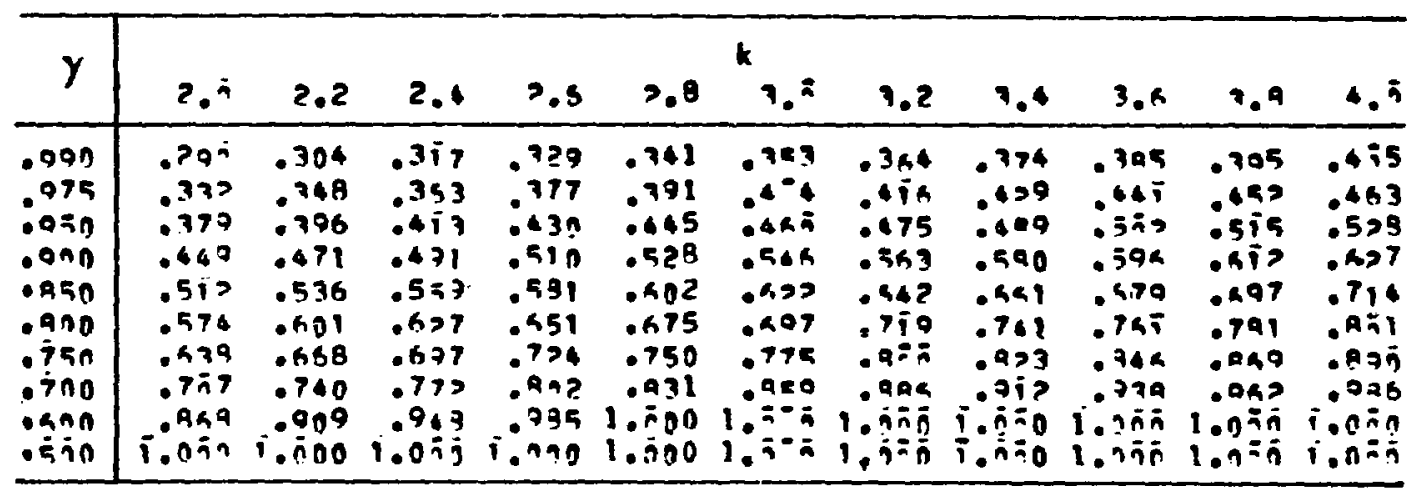


TABLE XIV

RI:QUIRIDD BAZI: TEST PLANS !OO.: THI: HIGH-PRESSUH: PUMP

\begin{tabular}{|c|c|c|c|c|c|c|c|c|c|c|c|}
\hline$y$ & 1.1 & 2.1 & 3.1 & .00 & 5.7 & 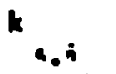 & $i,{ }^{2}$ & 9.9 & 1.7 & 13.7 & 11.0 \\
\hline 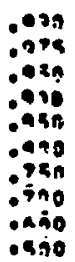 & 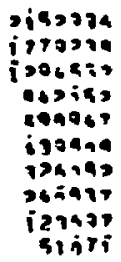 & 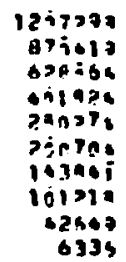 & 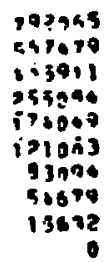 & 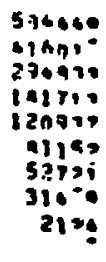 & 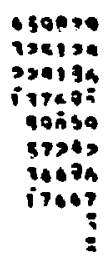 & 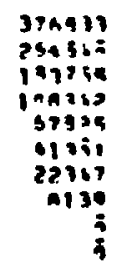 & 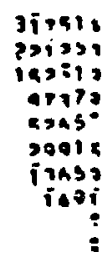 & $\begin{array}{r}273220 \\
106395 \\
124217 \\
71554 \\
61364 \\
21374 \\
7165\end{array}$ & 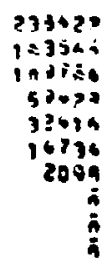 & $\begin{array}{r}21: 70 j \\
163314 \\
74703 \\
60465 \\
25335 \\
9621 \\
5 \\
5 \\
8 \\
8\end{array}$ & 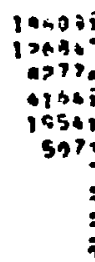 \\
\hline
\end{tabular}

TABLE XV

THE UNCONDITIONAL PROBABILITY OF PASSIAG THE CORRESPONDING BAEE TLSTS IN TABLI: XIV

\begin{tabular}{|c|c|c|c|c|c|c|c|c|c|c|c|}
\hline$y$ & 1.1 & 2.0 & 3.7 & 4.0 & 9.0 & k. & 7.0 & 0.0 & $9 . \overline{1}$ & $1 \dot{n} \cdot \hat{n}$ & 11.9 \\
\hline 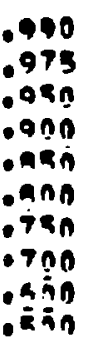 & $\begin{array}{l}.24= \\
.247 \\
.299 \\
.745 \\
.345 \\
.494 \\
.445 \\
.579 \\
.415 \\
.759\end{array}$ & $\begin{array}{r}.306 \\
.361 \\
.379 \\
.436 \\
.497 \\
.537 \\
.589 \\
.645 \\
.774 \\
.949\end{array}$ & $\begin{array}{l}.352 \\
.371 \\
.495 \\
.551 \\
.557 \\
.615 \\
.675 \\
.747\end{array}$ & 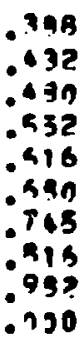 & $\begin{array}{r}.418 \\
.456 \\
.518 \\
.576 \\
.465 \\
.733 \\
.9194 \\
.990 \\
.790 \\
1.0700\end{array}$ & 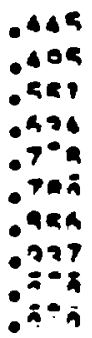 & 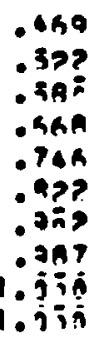 & 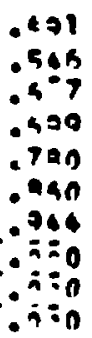 & 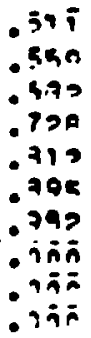 & 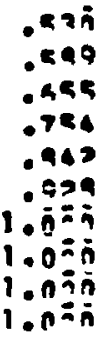 & 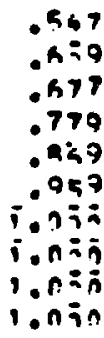 \\
\hline
\end{tabular}


TABLE: XV1

REQUIRLD BAZE TEST PLANG FOR TIIE RADIATOR

\begin{tabular}{|c|c|c|c|c|c|c|c|c|c|c|c|}
\hline & 7. & $\geqslant .2$ & 3.6 & 2.4 & $\because a$ & 1.7 & 1.7 & 3.0 & 3.6 & 3.3 & •.. \\
\hline 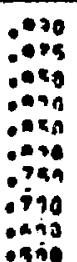 & 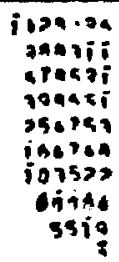 & 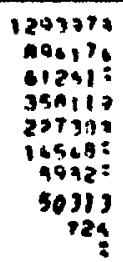 & 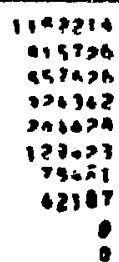 & 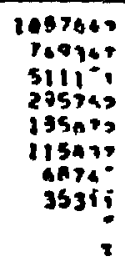 & 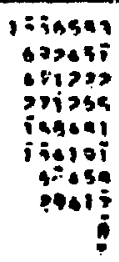 & 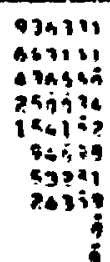 & 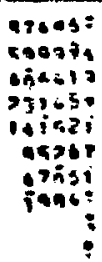 & $\begin{array}{l}527521 \\
501521 \\
379735 \\
315945 \\
135610 \\
77.75 \\
-1469 \\
15447\end{array}$ & 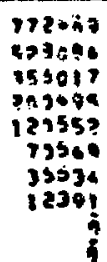 & $\begin{array}{r}129772 \\
677494 \\
330775 \\
137458 \\
111723 \\
40351 \\
32127 \\
0255\end{array}$ & $\begin{array}{r}0764 a \\
4755 a \\
315658 \\
175734 \\
193777 \\
50774 \\
36151 \\
4639 \\
3\end{array}$ \\
\hline
\end{tabular}

TABLE XVII

THE UNCONDITIOA:NL PROBALILITI OF PASSING THE CORRESPONDING BAEE TISSTS IN TABLE XVI

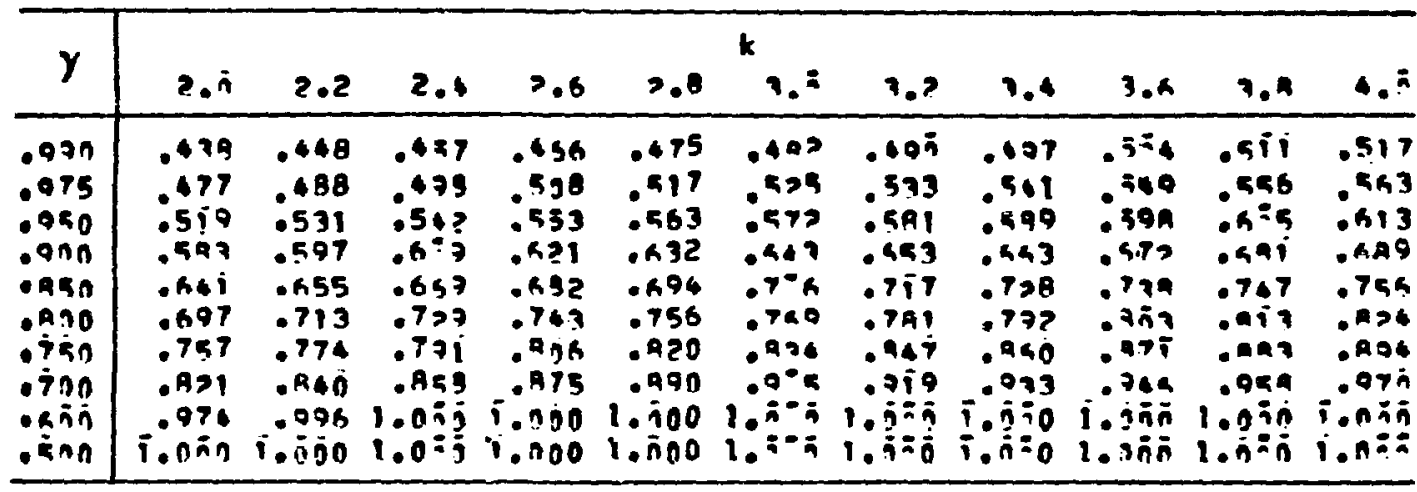


TABLE: IVIII

REQUIRID BAZI: TEST PLANS FOP THE THEMML

BY-PASS vH.VE, Flon LIMITER VAlKi.

AND FLOK CONTKOI. KMI:

\begin{tabular}{|c|c|c|c|c|c|c|c|c|c|c|c|}
\hline & 3.5 & 3.3 & 1.0 & 3.1 & $1 .=$ & 1. 7 & 1.5 & 4.4 & 4.5 & 1.9 & 5.0 \\
\hline 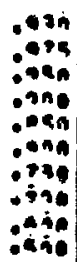 & 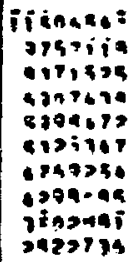 & 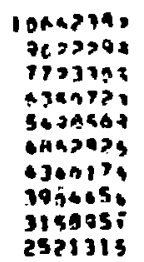 & 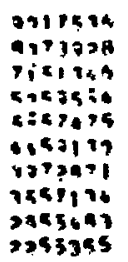 & 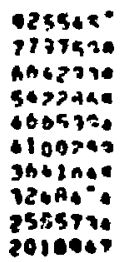 & 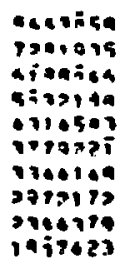 & 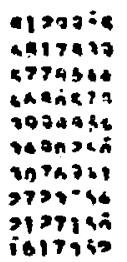 & 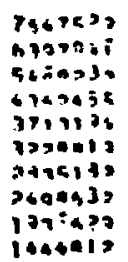 & 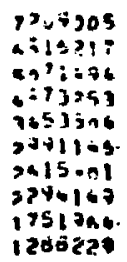 & 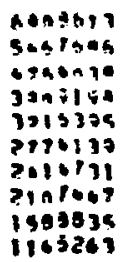 & 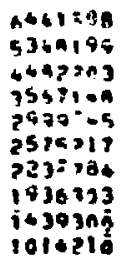 & 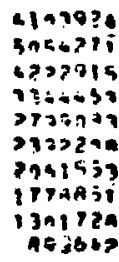 \\
\hline
\end{tabular}

TABLE $X I X$

THE UNCONDITIONAL PROBABILITY OF PASSING THE

CORRESPONDING BAEE TESTS IN TABLE XVIII

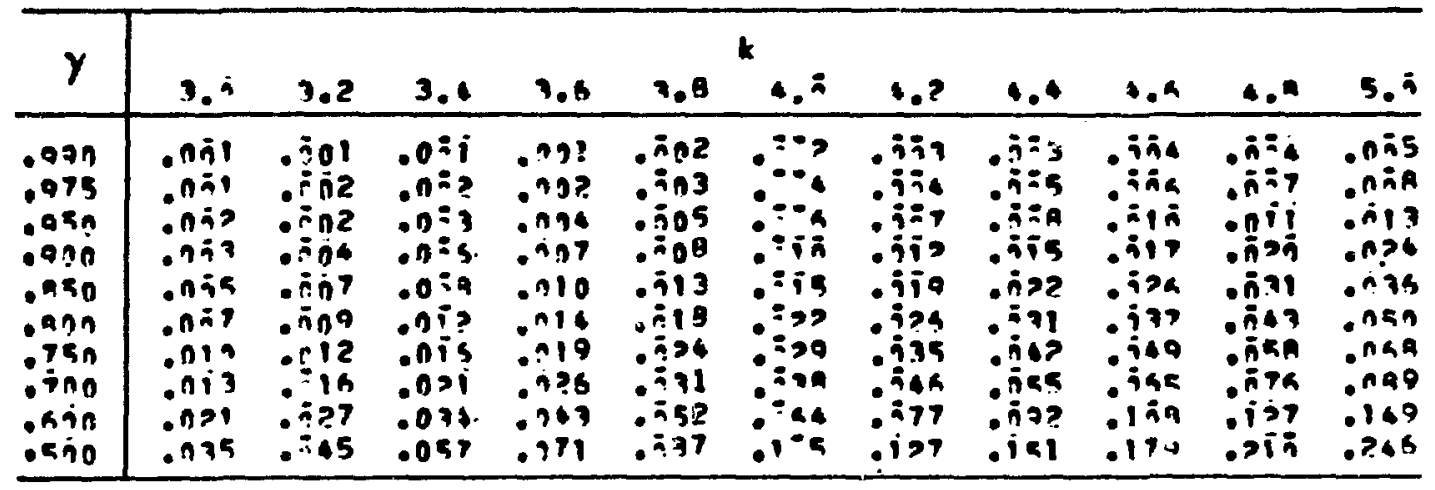


TABLE $X X$

RIQUIRED BAZI: TIST PLANS FOR TIIE RADIATOR

FILTER AND SCREEN FILTER

\begin{tabular}{|c|c|c|c|c|c|c|c|c|c|c|c|}
\hline$y$ & in.i & 10.7 & in.e & 10.0 & 20.7 & 29.1 & $29 . \pi$ & 31.0 & 30.0 & $37 .:$ & in.o \\
\hline 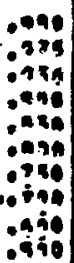 & 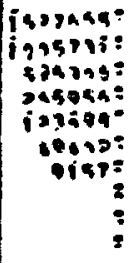 & $\begin{array}{r}i 243390 \\
1647550 \\
159263 i \\
195037 \\
640767 \\
24307 ! \\
\vdots\end{array}$ & 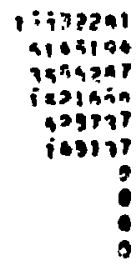 & 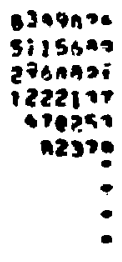 & 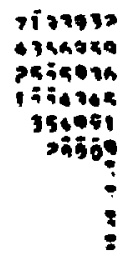 & 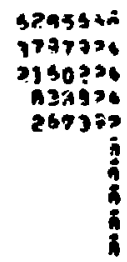 & 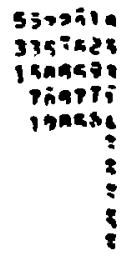 & $\begin{array}{r}1796503 \\
290 ; 251 \\
1009355 \\
60399 \\
143059 \\
\end{array}$ & 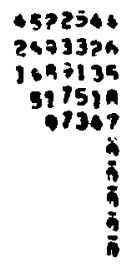 & $\begin{array}{r}4125608 \\
2664503 \\
1337559 \\
465151 \\
50=09 \\
8\end{array}$ & $\begin{array}{r}374701 ? \\
327317 \\
1279515 \\
34366 \\
26475 \\
\vdots\end{array}$ \\
\hline
\end{tabular}

TABLE XXI

THE UNCONDITIONAL PROBABILITY OF PASSING THE CORRESPONDING BAZE TESTS IN TABLE XX

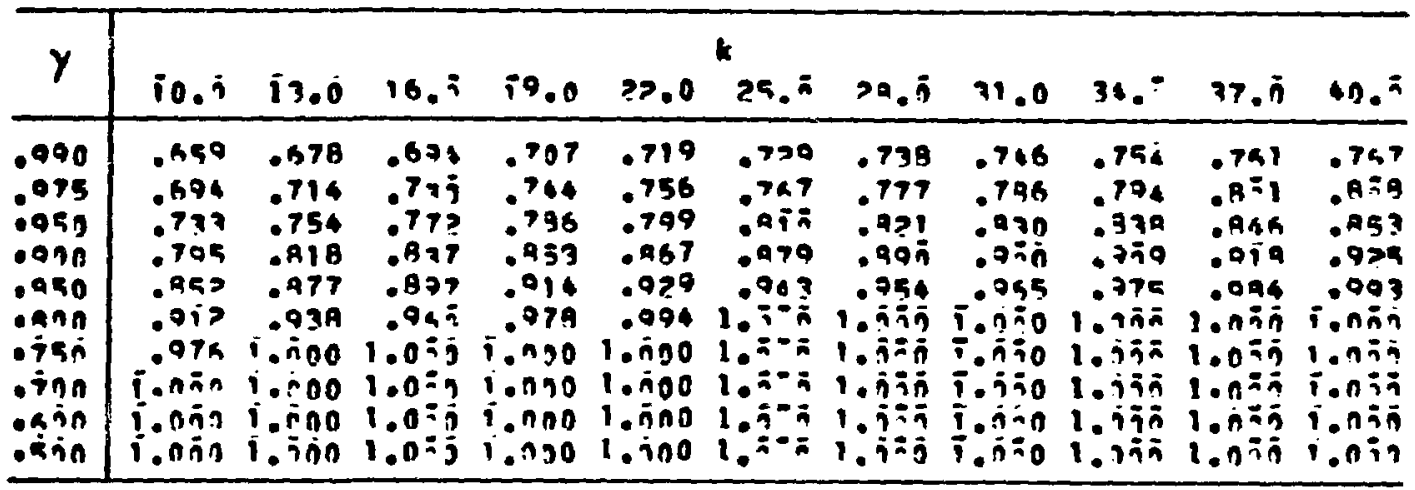


TABLE XXI I

REQUIRED BAZE TEST PLANS FOR THE TURBINE ASSEMBLY

\begin{tabular}{|c|c|c|c|c|c|c|c|c|c|c|c|}
\hline & 1.7 & $1 \cdot 3$ & 9.6 & 3.4 & 1.9 & 5. 1 & a.e & 6.5 & 7.6 & 9.2 & 0.0 \\
\hline 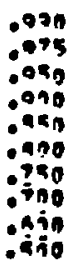 & 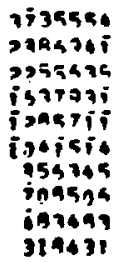 & 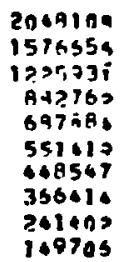 & 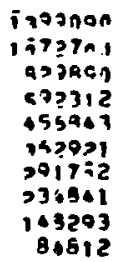 & 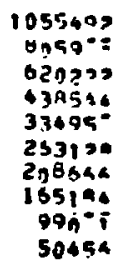 & 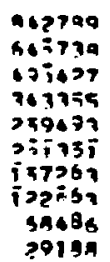 & 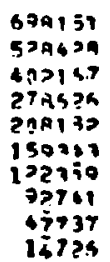 & 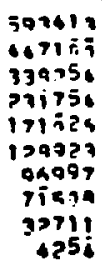 & $\begin{array}{l}514065 \\
385699 \\
289935 \\
196246 \\
142977 \\
105979 \\
77922 \\
55422 \\
21328\end{array}$ & $\begin{array}{r}.51975 \\
337197 \\
351684 \\
143617 \\
123815 \\
97915 \\
42797 \\
62414 \\
12656\end{array}$ & $\begin{array}{r}491919 \\
270329 \\
221341 \\
166-11 \\
163=57 \\
73277 \\
5=596 \\
32667 \\
5225\end{array}$ & $\begin{array}{r}34 n 655 \\
244371 \\
1762 ? 4 \\
1>7579 \\
44457 \\
41324 \\
46749 \\
24323\end{array}$ \\
\hline
\end{tabular}

TABLE XXIII

THE UNCONDITIONAL PROBABILITY OF PASSING THE CORRESPONDING BAZE TESTS IN TABLE XXII

\begin{tabular}{|c|c|c|c|c|c|c|c|c|c|c|c|}
\hline$y$ & $1 . i$ & 1.8 & 2.5 & 3.4 & 4.2 & 5.7 & 5.2 & 5.6 & 1.2 & Q.? & $9 . \overline{7}$ \\
\hline $\begin{array}{r}.990 \\
.975 \\
.990 \\
.900 \\
.950 \\
.9170 \\
.750 \\
.790 \\
.790 \\
.970 \\
.970\end{array}$ & 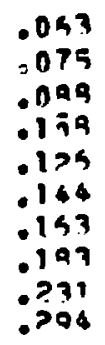 & $\begin{array}{l}.793 \\
.111 \\
1130 \\
160 \\
167 \\
187 \\
.714 \\
.742 \\
.77 \% \\
.743 \\
.436\end{array}$ & 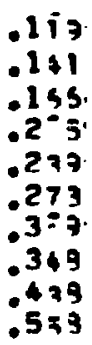 & $\begin{array}{r}143 \\
.159 \\
179 \\
.245 \\
.796 \\
.327 \\
.779 \\
416 \\
6525 \\
6958\end{array}$ & $\begin{array}{r}.155 \\
.195 \\
.729 \\
.792 \\
.730 \\
.777 \\
.426 \\
.490 \\
.405 \\
.770\end{array}$ & 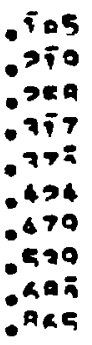 & 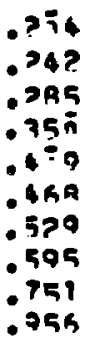 & $\begin{array}{l}.223 \\
.744 \\
.710 \\
.792 \\
.646 \\
.970 \\
.977 \\
.449\end{array}$ & 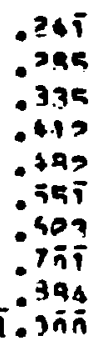 & $\begin{array}{l}.259 \\
.795 \\
.759 \\
.442 \\
.574 \\
.594 \\
.647 \\
.741 \\
.947\end{array}$ & $\begin{array}{l}.325 \\
.322 \\
.471 \\
.549 \\
.820 \\
.719 \\
.799 \\
09\end{array}$ \\
\hline
\end{tabular}


TABLE XXIV

REQUIRED BAZE TEST PLANS FOR THE ALTERNATOR

\begin{tabular}{|c|c|c|c|c|c|c|c|c|c|c|c|}
\hline$Y$ & 1.7 & 1.1 & 1.2 & 1.3 & 104 & 1.5 & i. 4 & 1.7 & 1.8 & 1.7 & 2.0 \\
\hline 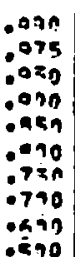 & 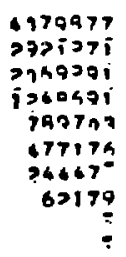 & $\begin{array}{r}3661270 \\
2594091 \\
1813676 \\
194747 \\
650710 \\
356594 \\
156545 \\
\vdots\end{array}$ & $\begin{array}{r}3075741 \\
2717276 \\
1959273 \\
015440 \\
533949 \\
373575 \\
79678 \\
0 \\
0\end{array}$ & $\begin{array}{r}2954519 \\
2775270 \\
14199 \% \\
7926 \% \\
43561= \\
1952 \div \\
162=\end{array}$ & 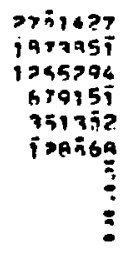 & $\begin{array}{r}2471574 \\
2690>31 \\
1131>76 \\
594>39 \\
278 \geqslant 35 \\
69934 \\
n \\
\hat{n} \\
\hat{n}\end{array}$ & 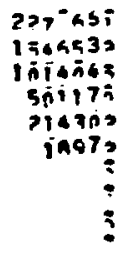 & $\begin{array}{r}2 \div 43287 \\
1411756 \\
910589 \\
427983 \\
157990 \\
0 \\
0 \\
0 \\
0\end{array}$ & $\begin{array}{r}1735521 \\
1391551 \\
313679 \\
332745 \\
107745 \\
\vdots \\
n \\
n\end{array}$ & $\begin{array}{r}1776551 \\
115659 \\
73634 \mathrm{e} \\
30645 \\
62380 \\
5 \\
50 \\
0 \\
0\end{array}$ & $\begin{array}{r}1647530 \\
1958234 \\
632276 \\
251974 \\
32571 \\
\end{array}$ \\
\hline
\end{tabular}

TABLE XXV

THE UNCONDITIONAL PROBABIIITY OF PASSING THE CORRESPONDING BAZE TESTS IN TABLE XXIV

\begin{tabular}{|c|c|c|c|c|c|c|c|c|c|c|c|}
\hline \multirow{2}{*}{$\gamma$} & \multicolumn{11}{|c|}{$\mathbf{k}$} \\
\hline & 1. & 1.1 & 1.? & 1.3 & 1.4 & 1.5 & $i . x$ & i. & 1.0 & 1.0 & $2 . \pi$ \\
\hline 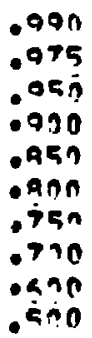 & $\begin{array}{l}.379 \\
.427 \\
.551 \\
.599 \\
607 \\
.777 \\
849 \\
.957 \\
0797\end{array}$ & 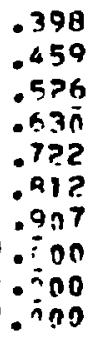 & $\begin{array}{l}.415 \\
.497 \\
.5=1 \\
.6=9 \\
.7=5 \\
.8=9\end{array}$ & $\begin{array}{r}.434 \\
.591 \\
.574 \\
.297 \\
.737 \\
.995 \\
009\end{array}$ & 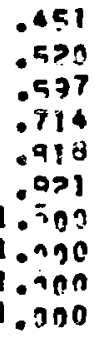 & 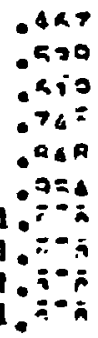 & 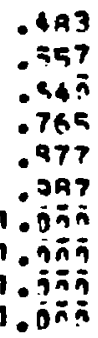 & $\begin{array}{r}409 \\
.575 \\
620 \\
.790 \\
990\end{array}$ & 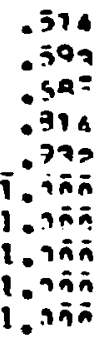 & 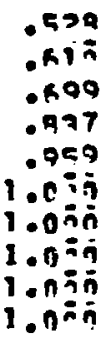 & $\begin{array}{r}.543 \\
.676 \\
.719 \\
.959 \\
.925 \\
.007 n \\
1.079 \\
1.07 n \\
1.07 n \\
1.070\end{array}$ \\
\hline
\end{tabular}


TABLE XXVI

REQUIRED BAZE TEST PLANS FOR THE REGENERATOR AND BOILER

\begin{tabular}{|c|c|c|c|c|c|c|c|c|c|c|c|}
\hline$y$ & $1 . i$ & 1.4 & 2.6 & 3.4 & 1.2 & $k_{5.5}$ & 5.9 & 6.6 & 7.6 & 9.2 & 9.0 \\
\hline 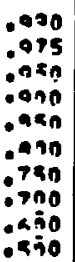 & 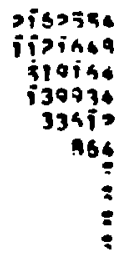 & $\begin{array}{r}1195774 \\
61769 \\
28779 \\
72597 \\
13727 \\
\vdots \\
\vdots\end{array}$ & $\begin{array}{r}123936 \\
63599 \\
191643 \\
69075 \\
5112 \\
n \\
0 \\
0 \\
0\end{array}$ & $\begin{array}{r}627041 \\
320979 \\
1+3791 \\
3210 ? \\
909 \\
\vdots \\
\vdots\end{array}$ & $\begin{array}{r}\text { sic2in } \\
357399 \\
\text { if 3934 } \\
2364 ! \\
\vdots \\
\vdots \\
\vdots\end{array}$ & $\begin{array}{r}422351 \\
216175 \\
93573 \\
17327 \\
5 \\
5 \\
5 \\
5 \\
5 \\
6\end{array}$ & $\begin{array}{r}36>34 \\
19>97 \% \\
700 \overline{0} \\
13619 \\
\vdots \\
\vdots\end{array}$ & $\begin{array}{r}316986 \\
159171 \\
67385 \\
10626 \\
5 \\
0 \\
0 \\
0 \\
0 \\
0\end{array}$ & 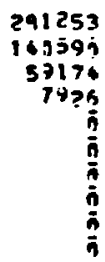 & $\begin{array}{r}252575 \\
125835 \\
52161 \\
5714 \\
0 \\
\frac{0}{0} \\
0 \\
0 \\
\frac{0}{0}\end{array}$ & $\begin{array}{r}228995 \\
113339 \\
6637 k \\
4259 \\
\vdots \\
\vdots \\
\vdots\end{array}$ \\
\hline
\end{tabular}

TABLE XXVII

THE UNCONDITIONAL PROBABILITY OF PASSING THE CORRESPONDING BAZE TESTS IN TABLE XXVI

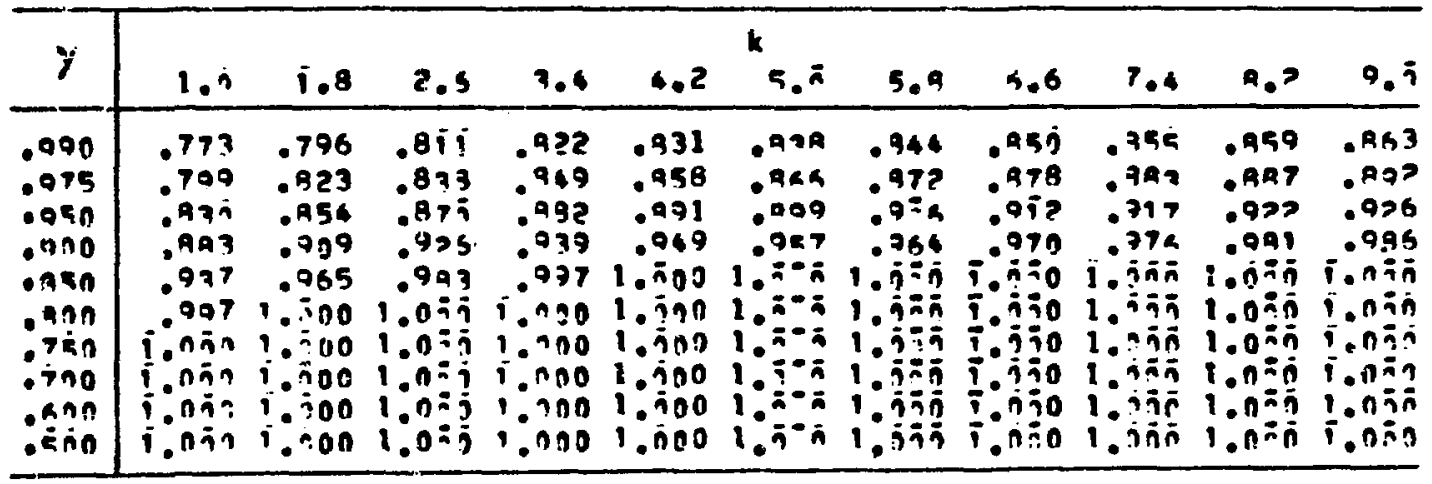


TABLE XXVI I I

REQUIRED BAZE TEST PLANS FOR THE REGENERATOR BY-PASS VALVE

\begin{tabular}{|c|c|c|c|c|c|c|c|c|c|c|c|}
\hline$y$ & $5 . \pi$ & 6.7 & T.0 & 9.0 & 9.5 & $k^{k} \overline{0}$ & 11.0 & 12.0 & {$[3.0$} & 14.8 & 15.0 \\
\hline 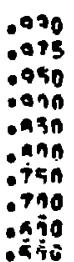 & $\begin{array}{r}779452 \\
5075 i 7 \\
725554 \\
54>79 \\
595 ! \\
\vdots \\
\vdots\end{array}$ & $\begin{array}{r}\text { A0836: } \\
414571 \\
146365 \\
42715 \\
244 ? \\
\vdots \\
\vdots\end{array}$ & $\begin{array}{r}491151 \\
153105 \\
157543 \\
30456 \\
0 \\
0 \\
0 \\
0 \\
0 \\
0\end{array}$ & $\begin{array}{r}60287= \\
307154 \\
135909 \\
2825 ? \\
\vdots \\
\end{array}$ & $\begin{array}{r}576277 \\
27 i 35 ? \\
719259 \\
23444 \\
\vdots \\
\vdots \\
\vdots\end{array}$ & $\begin{array}{r}479278 \\
242754 \\
175779 \\
19575 \\
5 \\
0\end{array}$ & $\begin{array}{r}434733 \\
219265 \\
94795 \\
15439 \\
\vdots \\
\vdots\end{array}$ & $\begin{array}{r}396980 \\
199739 \\
85632 \\
13973 \\
0 \\
0 \\
0 \\
0\end{array}$ & 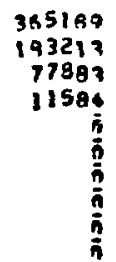 & $\begin{array}{r}33 A=26 \\
169-47 \\
71242 \\
9670 \\
0 \\
\frac{0}{0} \\
\frac{0}{0} \\
\frac{0}{0}\end{array}$ & $\begin{array}{r}314494 \\
15677 \\
65495 \\
1026 \\
\vdots \\
\vdots \\
\vdots \\
0\end{array}$ \\
\hline
\end{tabular}

TABLE XXIX

THE UNCONDITIONAL PROBABILITY OF PASSINE THE CORRESPONDING BAZE TESTS IN TABLE XXVIII

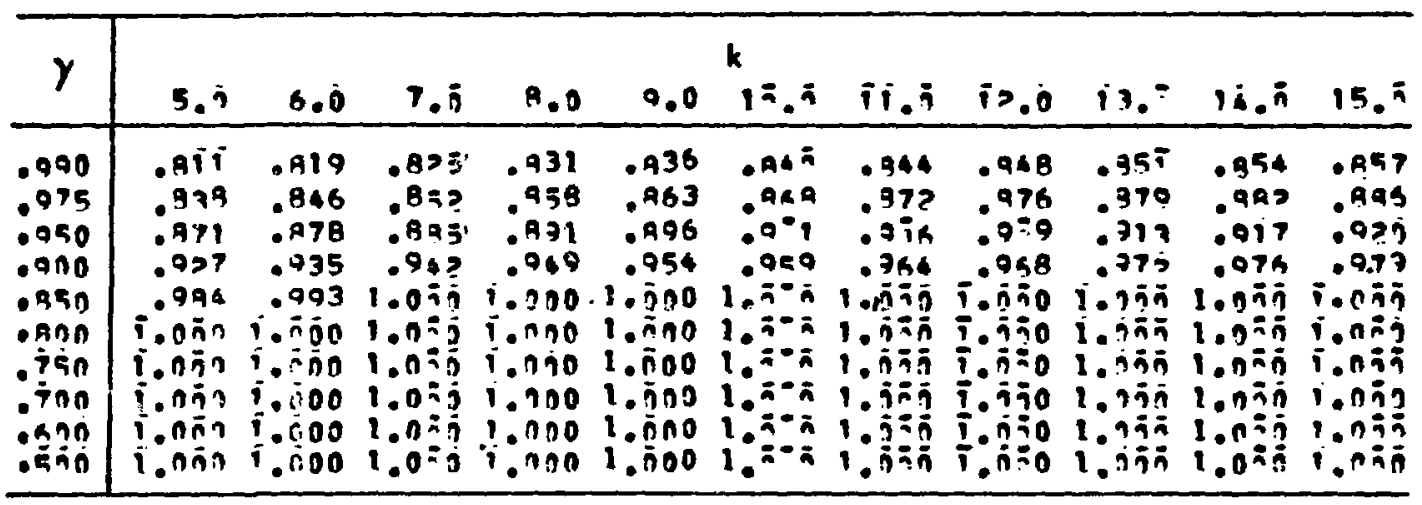


manner in which the BAZF procedure can be used to obtair test plans for testing cycle-dependent chance failure mechanisms. Second, we consider the manner in which BAZE component test plans can be developed taking into consideration a system failure-rate requirement. Third, we present a summary and give some conclusions.

A. Cycle-Dependent Chance Failure Mechanisms

Many of the components in the proposed Rankine PCS are iikely to possess failure modes related to cyclic operation. Such modes are likely to be exposed by the required FMEA (failure modes and effects analysis). To demonstrate the reliability of cyclically operated components, we consider testing $n$ items each for $N$ cycles of operation rather than a fixed time interval as used in the preceding cases. Under certain conditions, the BAZE testing procedure may be used to test those cyclically operated chance failure mechanisms by providing an approximate number of required test cycles. In particular, the procedure is useful when the number of cycles is large and the probability of failure on any cycle is small and approximately constant from cycle to cycle. The second assumption will likely hold if the test duration is contained within the useful life of the device and wear-related phenomena are negligibie or constant.

Let

$\lambda_{0}=$ specified failure-rate (failures/hr. of operation), $\mathrm{m}=$ required component duty cycle (cycles/hr.).

Then define

$\delta_{0}=\lambda_{0} / m=$ specified cycle failure-rate (failures/cycle). For specified $k$ and $\gamma$ as before, Table Al is entered to obtain $\theta_{\gamma}$. Once $\theta_{\gamma}$ has been obtained, the number of BAZE required unit-cycles of testing is found by calculatirg

$$
(\mathrm{nN})_{0}=\left(\theta_{\gamma}-\mathrm{bk} \delta_{0}\right) /\left(\mathrm{k} \delta_{0}\right) \text {. }
$$

A gamma prior distribution may still be used for the cycle failure-rate; however, the prior parameters $a$ and $b$ are now interpreted as the number of pseudo failures in a prior cycle life test of $b$ pseudo cycles of component operation. 


\section{Example:}

Let us illustrate the cycle BAZE procedure by means of an example. Consider a component, a valve say, for which we desire to demonstrate the failure-rate associated with cyclic failure mechanisms. The $\mathrm{SFR}$ is $\lambda_{0}=0.7 \times 10^{-6} \mathrm{fail-}$ ures/hr. and the parameters of the prior gamma distribution of $\lambda$ are $a=0.75$ and $b=1,071,429 \mathrm{hr}$. Further suppose that the duty cycle is $\mathrm{m}=1000 \mathrm{cycles} / \mathrm{yr} .=0.11416 \mathrm{cycles} / \mathrm{hr}$. Thus $\delta_{0}=6.132 \times 10^{-6}$ failures/cycle. Also, the value of the prior scale parameter $b$ in the distribution of $\delta$, the cycle failure-rate, is $b=122,314$ cycles. We take $k=1$ and $\gamma=$ 0.80 . From Table A1 we obtain $\theta_{0.80}=1.229561$. Thus, the required BAZE cycle test plan for this component is

$$
\begin{aligned}
(\mathrm{nN})_{0} & =\left[1.229561-(122,314)\left(6.132 \times 10^{-6}\right)\right] /\left(6.132 \times 10^{-6}\right) \\
& =78,202 \text { unit-cycles }
\end{aligned}
$$

of testing. Thus some possible test plans are to cycle 10 components 7,820 times each; 5 components for 15,640 cycles; etc. If no failures occur during the test, then it can be claimed that the true cycle failure-rate is less than $\delta_{0}$ with $80 \%$ assurance.

B. System Failure-Rate Considerations in Component Testing

Consider a system with $N$ components arranged in a series configuration. The system failure-rate $\lambda$ is related to the component failure-rates $\lambda_{i}$ by

$$
\lambda=\lambda_{1}+\cdots+\lambda_{N}=\sum_{i=1}^{N} \lambda_{i} .
$$

It is desired to determine BAZE component test plans which together assure that, if all component tests are passed, the system failurerate specification has been met.

The posterior distribution of $\lambda_{i}$, conditioned on no failures in a lifetest of duration $(n t)_{i}$ unit-hours, is a gamma distribution with mean $a_{i} /\left[b_{i}+(n t)_{i}\right]$ and variance $a_{i} /\left[b_{i}+(n t)_{i}\right]^{2}$, where $a_{i}$ and $b_{i}$ are the shape and scale parameters, respectively, for the $i^{\text {th }}$ component. If the component failures are statistically independent, then the posterior distribution of $\lambda$, conditional on all 
component 1 ifetests being passed, can be approximated by a gamma distribution. The mean and variance of this distribution, in terms of component means and variances, are given by

and

$$
E(\lambda \mid a 11 \text { component tests are passed })=\sum_{i=1}^{N} a_{i} /\left[b_{i}+(n t)_{i}\right]
$$

$$
V(\lambda \mid \text { al1 component tests are passed })=\sum_{i=1}^{n} a_{i} /\left[b_{i}+(n t)_{i}\right]^{2} \text {. }
$$

Now, the shape and scale parameters of the approximate posterior gamma distribution of $\lambda$ are given by

and

$$
a=\left\{\sum_{i=1}^{N} a_{i} /\left[b_{i}+(n t)_{i}\right]\right\}^{2} / \sum_{i=1}^{N} a_{i} /\left[b_{i}+(n t)_{i}\right]^{2}
$$

$$
b=\sum_{i=1}^{N} a_{i} /\left[b_{i}+(n t)_{i}\right] / \sum_{i=1}^{N} a_{i} /\left[b_{i}+(n t)_{i}\right]^{2} \text {. }
$$

The objective of the system's approach taken here is to obtain the minimum cost BAZE component demonstration test plans which assure that the required system failure-rate specification has been met. Let us now identify certain costs associated with component demonstration testing. Define

where

$$
\begin{aligned}
c_{i} & =\text { total cost of testing the } i^{\text {th }} \text { component per unit-hour } \\
& =c_{i 0}+c_{i 1}+c_{i 2},
\end{aligned}
$$

(i) $\quad c_{i 0}=$ component $\cos t$ of the $i^{\text {th }}$ component per unithour,

(ii) $c_{i 1}=$ test facility and test instrumentation cost of the $i^{\text {th }}$ component per unit-hour,

(iii) $c_{i 2}=$ operation cost of the $i^{\text {th }}$ component per unithour.

The problem is now to find BAZE component test plans which minimize the total testing cost while providing assurance that the component test plans satisfy the required system failure-rate specification. In mathematical terms, we wish to 
find $(n t)_{1},(n t)_{2}, \cdots,(n t)_{N}$ which

$$
\operatorname{minimizes} \sum_{i=1}^{N} c_{i}(n t)_{i}
$$

suiject to the constraints

(i) $(n t)_{i} \geq 0, i=1, \cdots, N$,

(ii) I $\left(a, b k \lambda_{0}\right)-\gamma \Gamma(a)=0$,

where $\left(k \lambda_{0}\right)$ is the criterion failure-rate and $\gamma$ is the probability that this failure-rate has been attained. The standard techniques of non-linear mathematical programining can be used to solve this problem. This will be the subject of a future technical report.

C. Summary and Conclusions

A Bayesian zero-failure (BAZE) reliability demonstration testing procedure is developed. The procedure assumes that the component failure-rate is a constant value of a random variable having a gamma prinr distribution. The testing procedure is to place $n$ items on lifetest with replacement for a specified length of time $t$. The lifetest is passed if no failures occur. The quantity of testing required, the test plan, is found by considering a single criterion. In a test that is passed, the conditional probability that the failure-rate does not exceed a prespecified value is set equal to a desired posterior assurance.

The BAZE procedure can be used to statistically verify failure-rates associated with real-time chance failure mechanisms. In certain cases, the procedure can also be used to statistically verify failure-rates for cycle-dependent chance failure mechanisms.

The BAZE procedure is used here to obtain sample test plans for demonstrating the real-time dependent failure effects of the components of a proposed Rankine power conversion system. For most of these components, large quantities of testing are required to demonstrate the small specified failure-rates with even reasonable assurance. This is largely the result of fitted prior distributions whose means are significantly greater than the 
specified failure-rates. This is a pessimistic result which requires the producer to support projected low component failurerates with significant quantities of testing. This insures adequate consumer protection against accepting component hardware with unacceptably high failure-rates.

Several aspects of reliability demonstration testing are not considered here. No attempt has been made to identify specific methodologies for testing classes of components such as valves, filters, etc. Before the BAZE procedure $c$ an be used in practice several things must be considered. First, the life cycle of each component must be identified. This includes establishing the environments and operating conditions to which each component is exposed during the various phases of its existence. This also includes defining the duty cycle for the operational phases. Second, the possible failure mechanisms need to be identified. This can be accomplished by means of an FMEA. Third, the BAZE procedure can be used to demonstrate either individual or collective failure modes by carefully defining the criteria which describe component failure. In other words, the practical details of implementing the BAZE procedure have not been addressed in this report. This would ordinarily occur as part of the contractor's reliability program plan.

Fina11y, the main advantage of the BAZE procedure over other Bayesian demonstration test procedures is its ease of application. In most instances, Table A1 and a pocket calculator are sufficient for calculating the BAZE test plans. The most 1aborious tasks in using the procedure are determining a satisfactory prior distribution and stating values of the posterior assurance and discrimination ratio. However, all Bayesian procedures share similar steps in their application.

\section{Acknowledgments}

The authors wish to thank Ms. Carla McInteer and Ms. Merle Horita for their help in computing Table Al in the Appendix. 
$\underline{\text { References }}$

1. Balaban, H., "A Bayesian Approach to Reliability Demonstration," Anna1s of Assurance Sciences, Vo1. 8, 1969, pp, 497506.

2. Balaban, H., "Reliability Demonstration: Purposes, Practices, and Value," Proceedings of the 1975 Annual Reliability and Maintainability Symposium, Washington, D.C., 1975, pp. 246248 .

3. Blumentha1, S., "Re1iability Demonstration," Technical Report No. 183, Department of Operations Research, Corne11 University, Ithaca, NY, May 1973.

4. Bonis, A. J., "Bayesian Reliability Demonstration P1ans," Reliability and Maintainability Conference, Vol. 5, 1966 , pp. 861-870.

5. Easterling, R. G., "On the Use of Prior Distributions in Acceptance Sampling," Annals of Reliability and Maintainability, Vo1. 9,1970, pp. 31-35.

6. Goel, A. L. and Joglekar, A. M., "Reliability Acceptance Sampling Plans Based Upon Prior Distribution, Technical Reports 76-1 to 76-5, Department of Industria1 Engineering and Operations Research, Syracuse University, Syracuse, NY, March 1976.

7. Goe1, A. L. et a1., "Re1iability Demonstration Plans Using Prior Distribution," Technical Report, Department of Industrial Engineering and Operations Research, Syracuse Univer sity, Syracuse, NY.

8. Goel, A. L. et a1., "Graphica1 Design of Reliability Demonstration Plans Based upon Prior Distribution," Technical Report, Department of Industrial Engineering and Operations Research, Syracuse University, Syracuse, NY.

9. Gui1d, R. D., "Bayesian MFR Life Test Sampling Plans," Journal of Quality Technology, Vo1. 5, 1973, pp. 11-15.

10. Guild, R. D., "Reliability Testing and Equipment Design Using Bayesian Mode1s," Unpublished Ph.D. Dissertation, Northwestern University, Evanston, IL, 1968.

11. Joglekar, A. M., "Reliability Demonstration Based on Prior Distribution - Sensitivity Analysis and Multi Sample Plans," Proceedings of the 1975 Annual Reliability and Maintainabil ity Symposium, Washington, D.C., 1975, pp. 251,252. 
12. Mann, N. R., Schafer, R. E., and Singpurwalla, N. D., Methods for Statistical Analysis of Reliability and Life Data, Wiley, Inc., 1974 .

13. Martz, H. F. and Waller, R. A., "The Basics of Bayesian Reliabiiity Estimation from Attribute Test Data," Report No. LA-6126, Los Alamos Scientific Laboratory, 1976.

14. MIL-STD-781C, Reliability Tests: Exponential Distribution, U.S. Government Printing Office, Washington, D.C.

15. Ramos, J. R., "Development of Bayesian Life Test Sampling Plans Assuming a Failure Rate with a Gamma Prior Distribution," Unpublished M.S. Thesis, The Pennsylvania State University, University Park, PA, 1970.

16. Schafer, R. E., "Bayesian Reliability Demonstration: Phase I - Data for the A Priori Distribution," RADC-TR-69-389, 1969 .

17. Schafer, R. E., "Bayesian Reliability Demonstration: Phase III - Development of Test Plans," RADC-TR-73-139, 1973.

18. Schafer, R. E. and Sheffield, T, S., "Bayesian Reliability Demonstration: Phase II - Development of a Prior Distribution," RADC-TR-71-209, DDC AD-732283, 1971.

19. Schafer, R. E. and Singpurwa11a, N. D., "A Sequential Bayes Procedure for Reliability Demonstration," Naval Research Logistics Quarterly, Vol. 17, 1970, pp. 55-67.

20. Waller, R. A. and Martz, H. F., "Bayesian Reliability Estimation: State of the art for the Time-Dependent Case," Report No. LA-6003, Los Alamos Scientific Laboratory, 1975. 


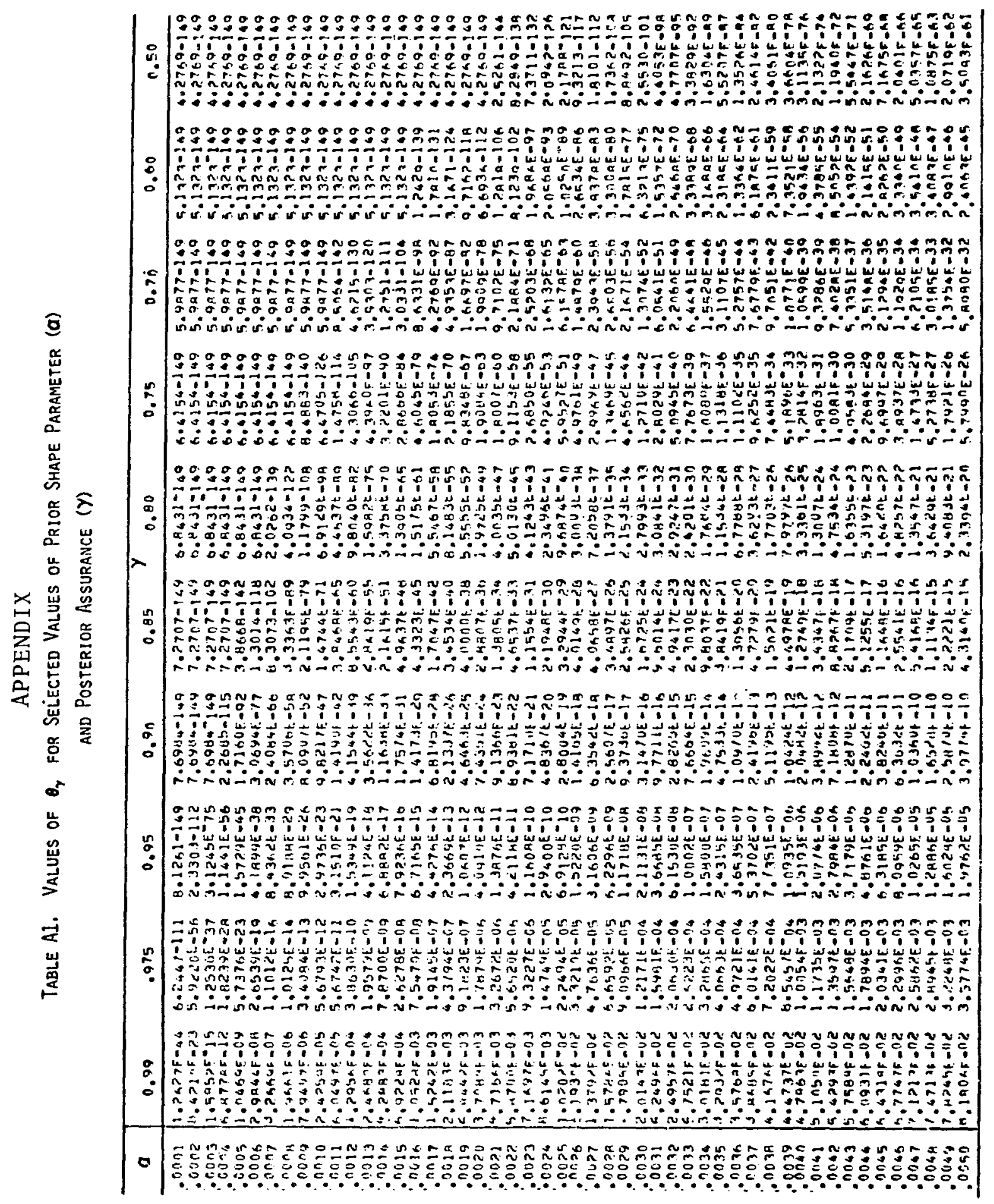




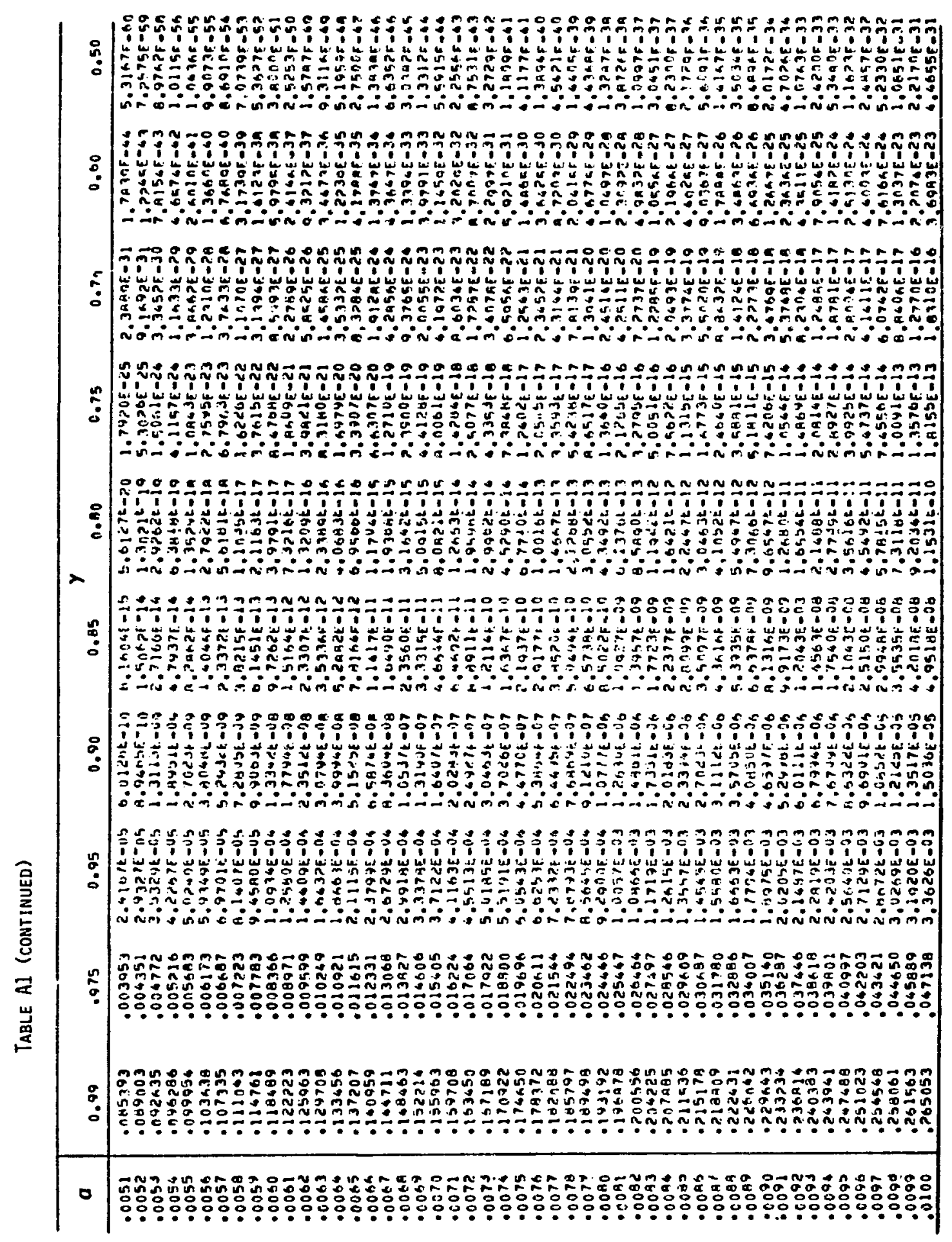




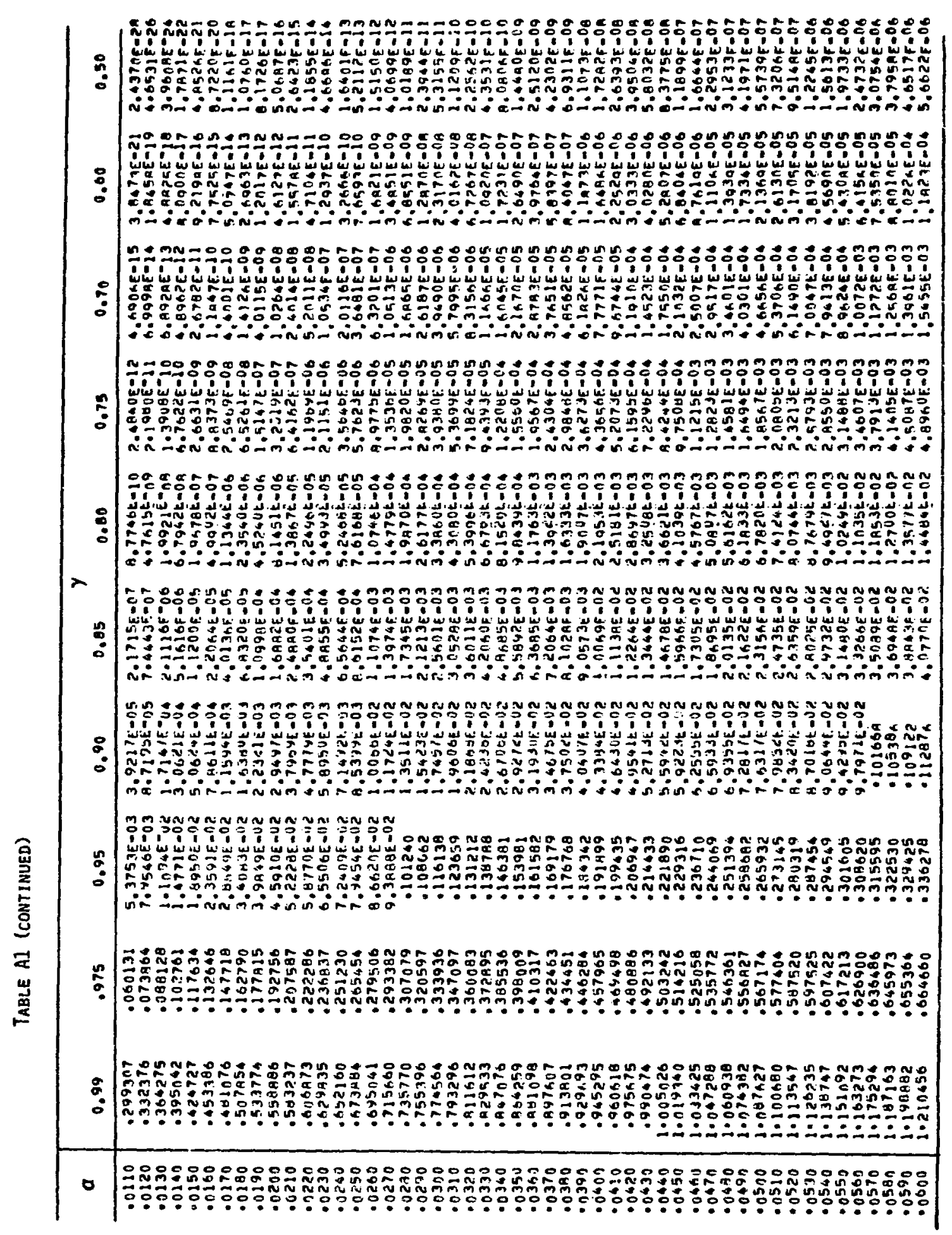




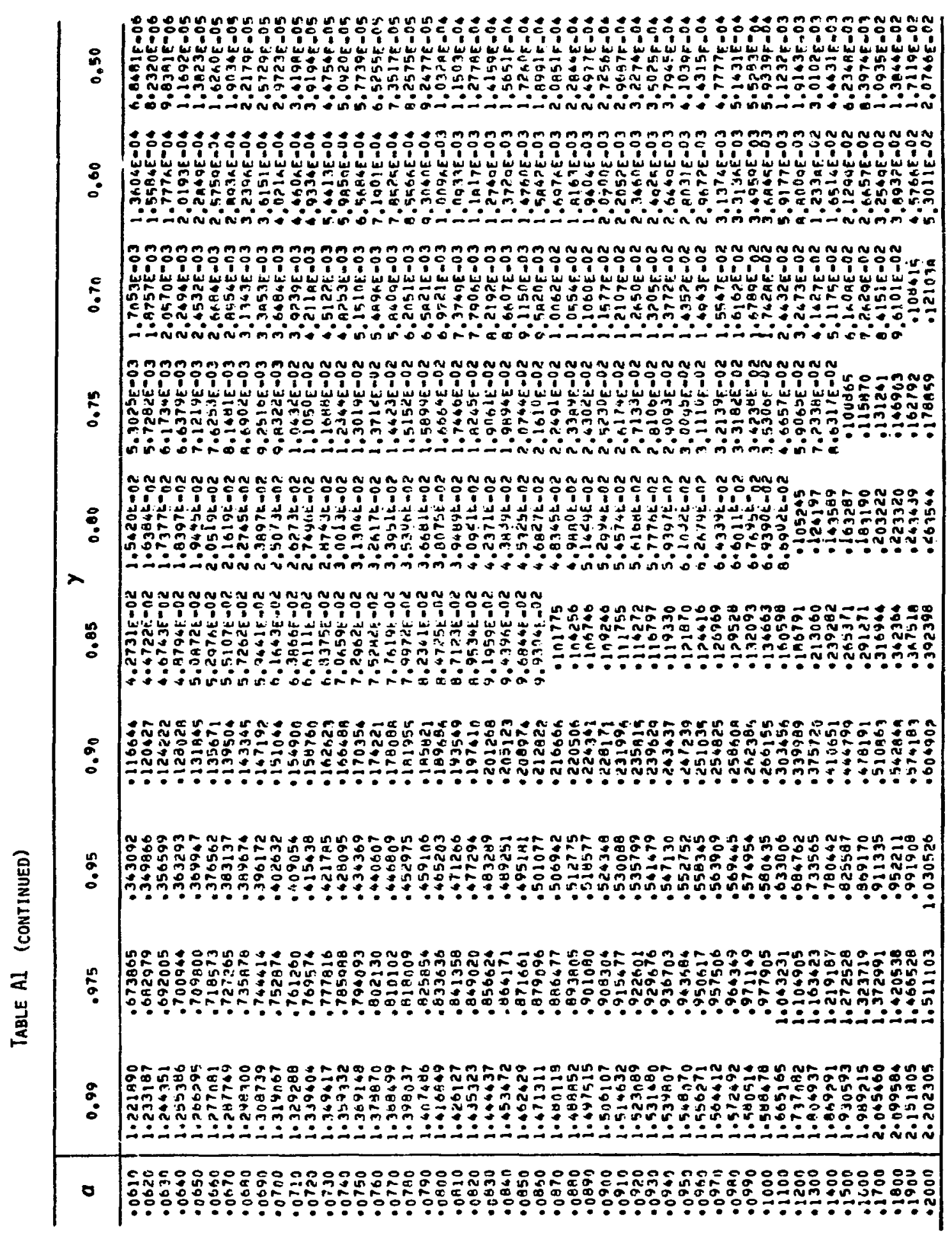




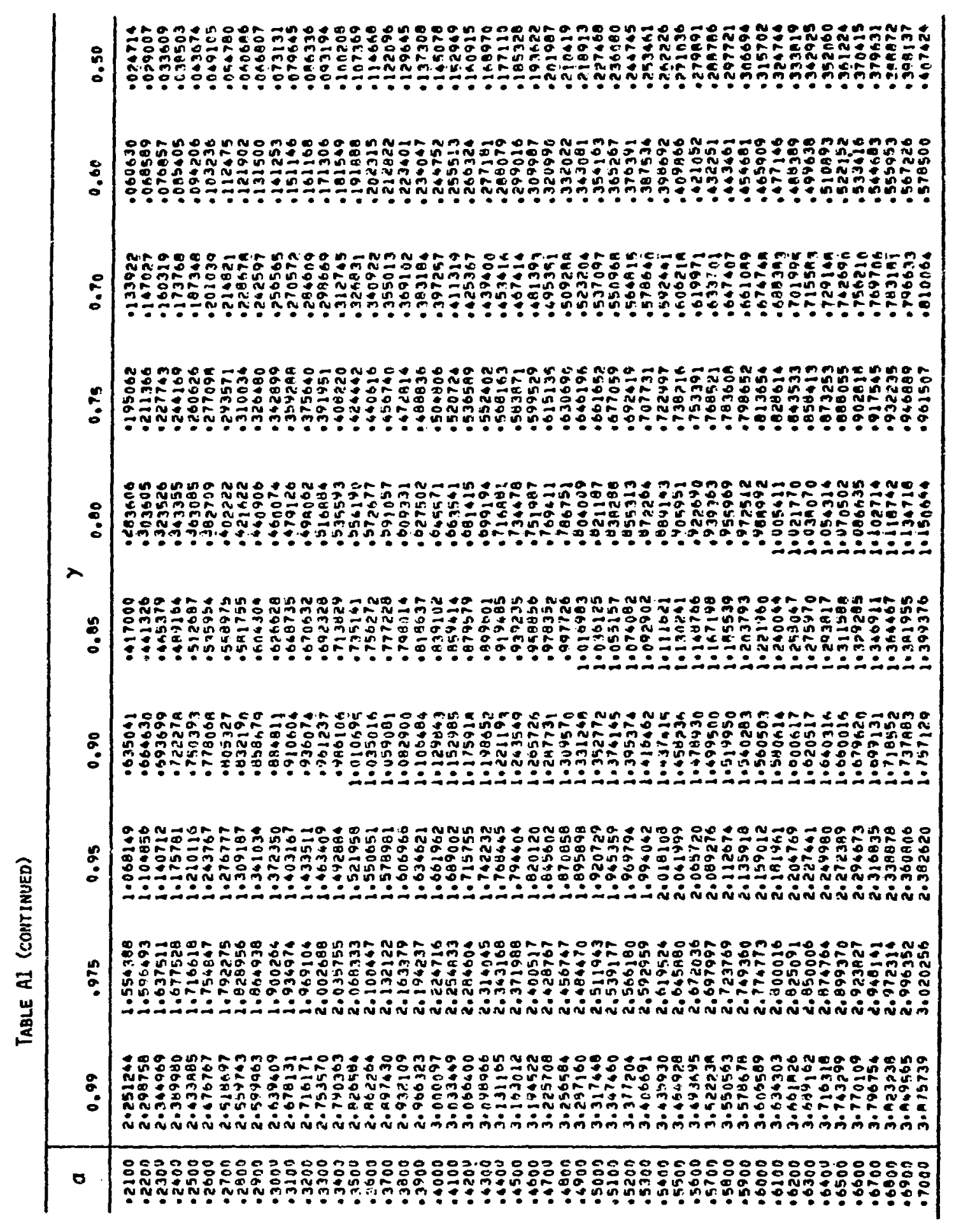




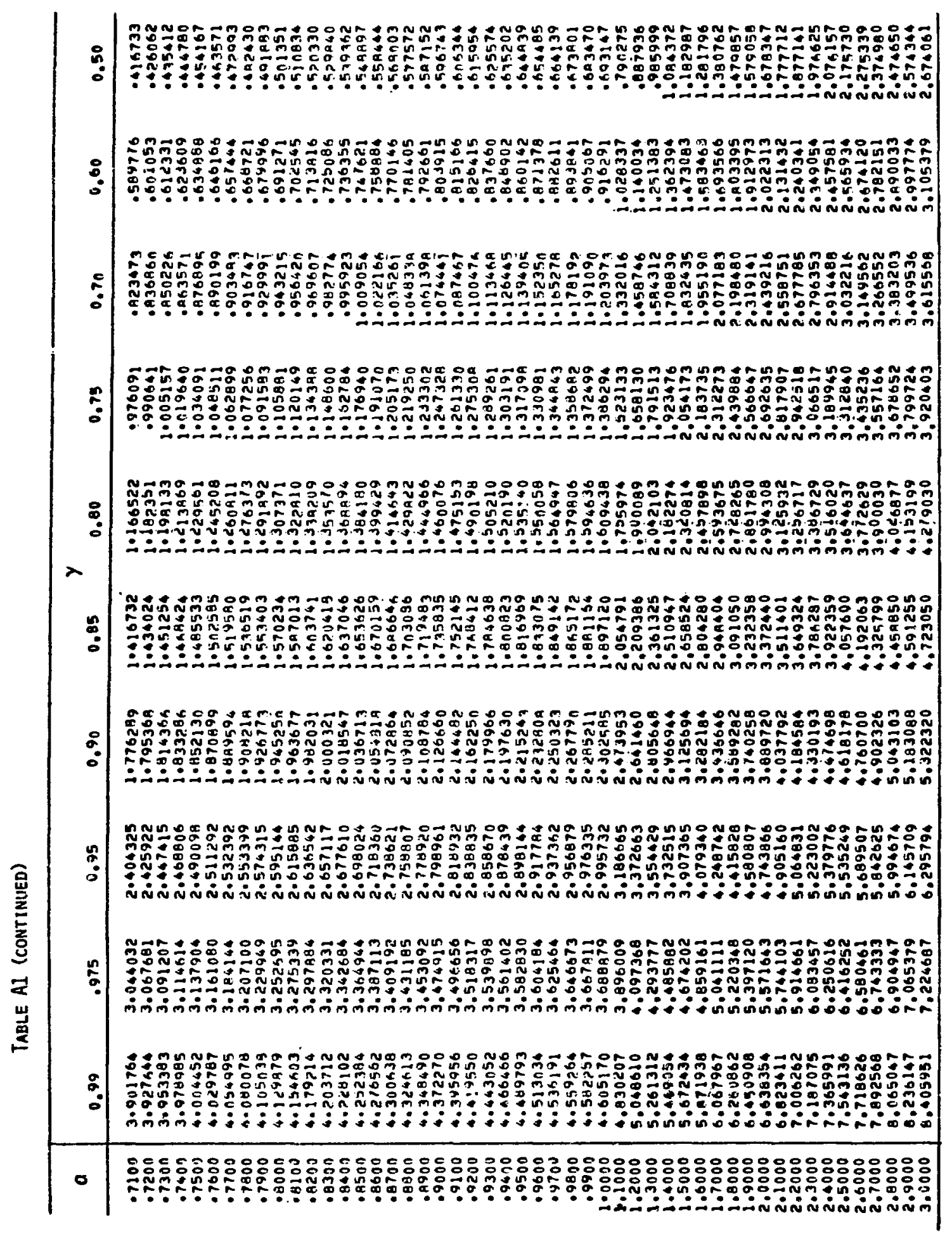




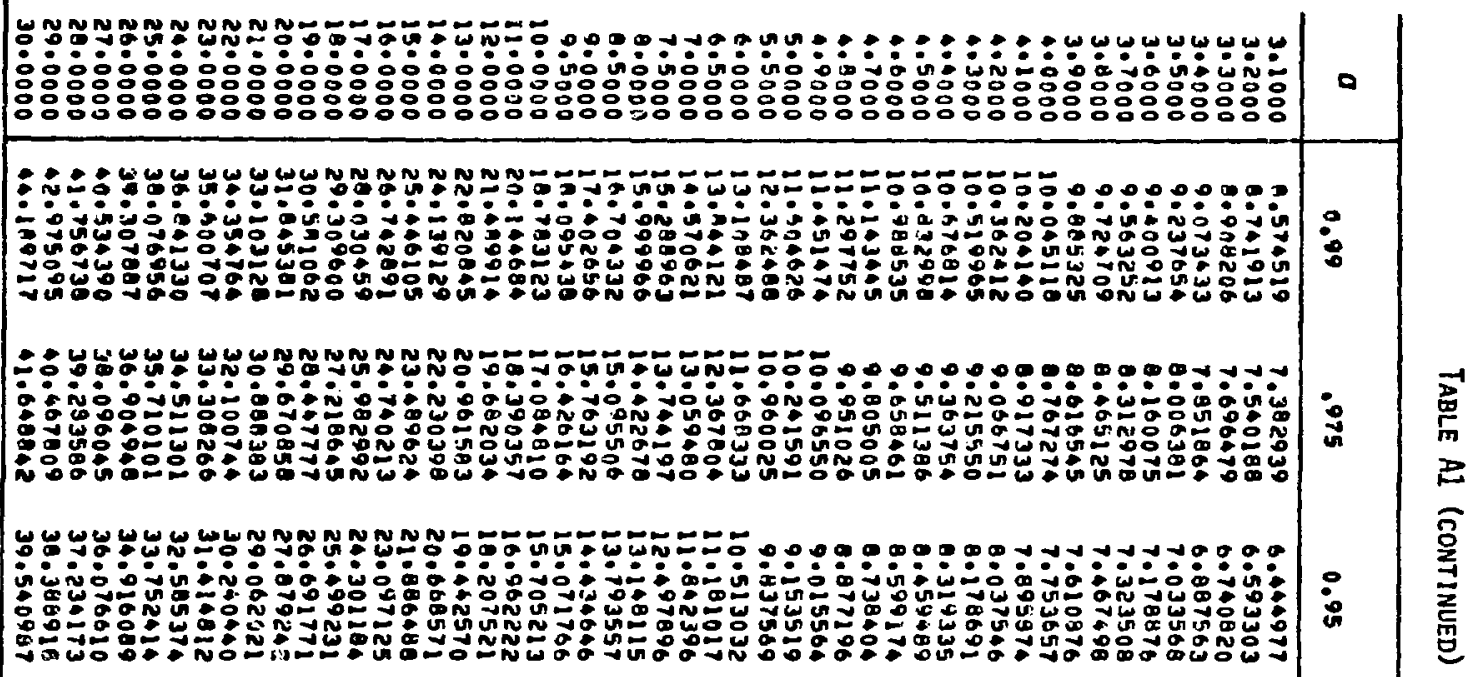

แัะ

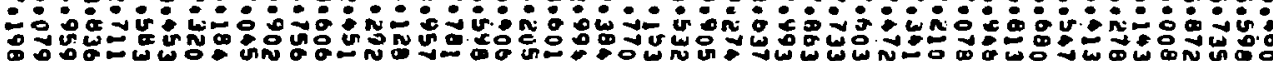

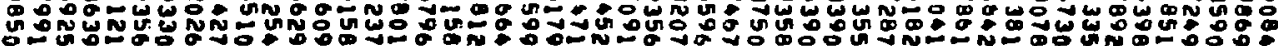

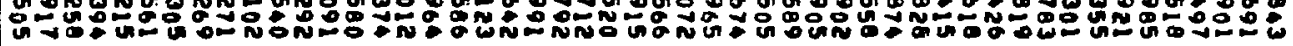

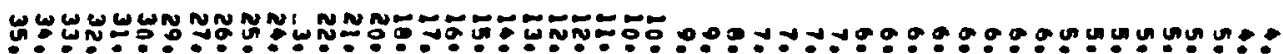

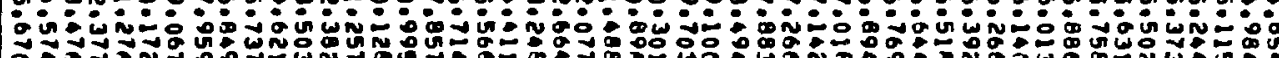
品:

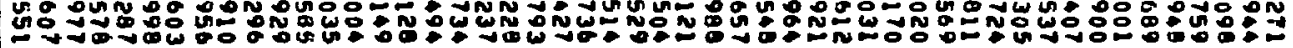

W W

: ㄴ.: : Ln: D :

廿 : 罗

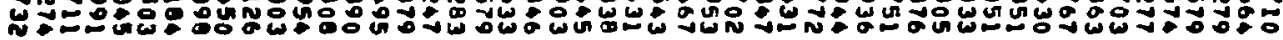

WWWNNNNYN UNN

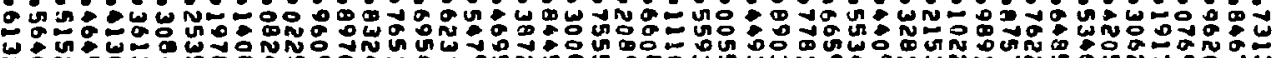

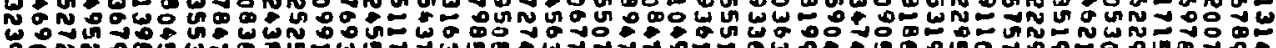

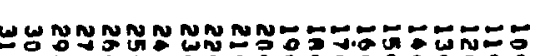

:

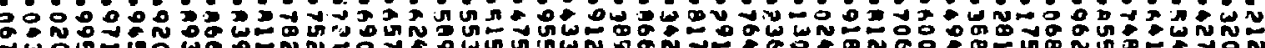
†

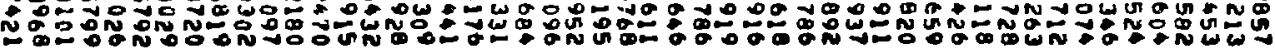

บN บNN

年

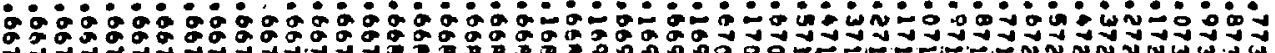

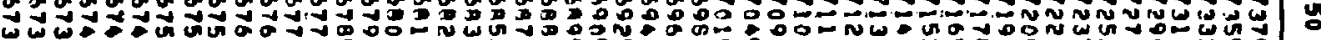
岁出 
Table Al (Continued)

\begin{tabular}{|c|c|c|c|c|c|c|c|c|c|c|}
\hline a & 0.09 & .975 & 0.95 & 0.90 & 0.85 & 0.00 & 0.75 & 0.70 & 0.60 & 0.50 \\
\hline $\begin{array}{l}31.0000 \\
32.0000 \\
3300000 \\
3400000 \\
35.0000 \\
3600000 \\
37.0000 \\
38.0000 \\
39.0000 \\
4000000 \\
41.0000 \\
4200000 \\
4300000 \\
4400000 \\
4500000 \\
46.0000 \\
47.0000 \\
4600000 \\
4900000 \\
50.00000\end{array}$ & $\begin{array}{l}45.400776 \\
46.508444 \\
47.912669 \\
49.014226 \\
50.212586 \\
51.0198107 \\
52.601029 \\
53.791297 \\
50.979045 \\
56.164393 \\
57.347484 \\
58.528289 \\
59.706962 \\
60.093584 \\
62.158173 \\
63.230860 \\
64.401640 \\
65.570640 \\
66.737841 \\
67.903375\end{array}$ & $\begin{array}{l}42.026876 \\
440002030 \\
45.174450 \\
46.346280 \\
47.511599 \\
48.676511 \\
49.839163 \\
50.999632 \\
52.157977 \\
53.314291 \\
54.068656 \\
55.621137 \\
56.771796 \\
57.920722 \\
59.067953 \\
60.213551 \\
61.357533 \\
62.500050 \\
63.041014 \\
64.780609\end{array}$ & $\begin{array}{l}40.690505 \\
61.037637 \\
426982466 \\
64.125005 \\
45.265616 \\
46.409120 \\
47.540735 \\
48.675488 \\
49.008471 \\
50.939748 \\
52.069372 \\
53.197424 \\
54.323951 \\
55.449005 \\
56.572638 \\
57.694699 \\
54.815828 \\
59.935454 \\
61.053858 \\
62.171059\end{array}$ & 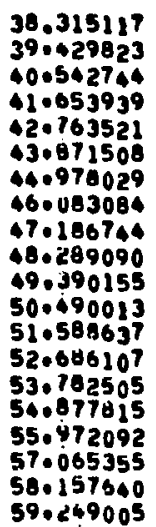 & $\begin{array}{l}36.764687 \\
37.857699 \\
38.949060 \\
40.039020 \\
41.127677 \\
42.215054 \\
43.301215 \\
44.384209 \\
45.470082 \\
46.552879 \\
47.634639 \\
48.715385 \\
49.795186 \\
50.874063 \\
51.952057 \\
53.029132 \\
54.105397 \\
55.180846 \\
56.255501 \\
57.329410\end{array}$ & 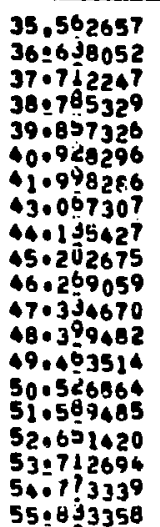 & $\begin{array}{l}34.552154 \\
35.612575 \\
35.672057 \\
37.730619 \\
30.788329 \\
39.845226 \\
40.901293 \\
41.956629 \\
43.011231 \\
44.065116 \\
45.116356 \\
46.170926 \\
47.222861 \\
46.274212 \\
49.324967 \\
50.375165 \\
51.424800 \\
52.473497 \\
53.522507 \\
54.570622\end{array}$ & $\begin{array}{l}33.661009 \\
34.707970 \\
35.754229 \\
36.799770 \\
37.844639 \\
34.698883 \\
39.932480 \\
40.975497 \\
42.017969 \\
43.059856 \\
44.101228 \\
450142096 \\
46.182505 \\
47.222420 \\
46.261898 \\
49.300905 \\
50.33950 A \\
51.377691 \\
52.415450 \\
53.452881\end{array}$ & $\begin{array}{l}32.090473 \\
33.113172 \\
34.135515 \\
35.157496 \\
36.179174 \\
37.200535 \\
31.221599 \\
39.242375 \\
41.262888 \\
41.283126 \\
42.303114 \\
43.322840 \\
44.342367 \\
45.361649 \\
46.360712 \\
47.399561 \\
46.418206 \\
49.436650 \\
50.454918 \\
51.472973\end{array}$ & $\begin{array}{l}30.667311 \\
31.667291 \\
32.667272 \\
33.667250 \\
34.067230 \\
35.667222 \\
36.667205 \\
37.667198 \\
38.067170 \\
39.667166 \\
40.667153 \\
41.667162 \\
42.667131 \\
43.667121 \\
44.667110 \\
45.667100 \\
46.657091 \\
47.667092 \\
46.667073 \\
49.667065\end{array}$ \\
\hline
\end{tabular}

